(C) The Author(s), 2021. Published by Cambridge University Press on behalf of The Nutrition Society. This is an Open Access article, distributed under the terms of the Creative Commons Attribution licence (http://creativecommons.org/licenses/by/4.0/), which permits unrestricted re-use, distribution, and reproduction in any medium, provided the original work is properly cited.

\title{
Vitamin D and acute and severe illness - a mechanistic and pharmacokinetic perspective
}

\author{
Inez Schoenmakers $^{1}$ (D), William D. Fraser ${ }^{1}$ and Alastair Forbes ${ }^{1,2}$ \\ ${ }^{1}$ Norwich Medical School, Faculty of Medicine and Health Sciences, University of East Anglia, UK \\ ${ }^{2}$ Institute of Clinical Medicine, University of Tartu, Estonia
}

\section{Abstract}

The coronavirus disease 2019 (COVID-19) pandemic has generated high interest in factors modulating risk of infection, disease severity and recovery. Vitamin D has garnered interest since it is known to modulate immune function and vitamin D deficiency is associated with increased risk of respiratory infections and adverse health outcomes in severely ill patients. There are no population representative data on the direct relationship between vitamin D status and severe acute respiratory syndrome coronavirus 2 infection risk and severity of COVID-19. Data from intervention studies are limited to four studies. Here we summarise findings regarding vitamin D status and metabolism and their alterations during severe illness, relevant to COVID-19 patients. Further, we summarise vitamin D intervention studies with respiratory disease outcomes and in critically ill patients and provide an overview of relevant patient and population guidelines. Vitamin D deficiency is highly prevalent in hospitalised patients, particularly when critically ill, including those with COVID-19. Acute and critical illness leads to pronounced changes in vitamin D metabolism and status, suggestive of increased requirements. This needs to be considered in the interpretation of potential links between vitamin D status and disease risk and severity and for patient management. There is some evidence that vitamin D supplementation decreases the risk of respiratory tract infections, while supplementation of intensive care unit patients has shown little effect on disease severity or length of treatment. Considering the high prevalence of deficiency and low risks associated with supplementation, pro-actively applying current population and patient management guidelines to prevent, monitor and correct vitamin D deficiency is appropriate.

\section{Keywords: Vitamin D: Respiratory disease: Critical illness: COVID-19}

(Received 17 November 2020; revised 2 July 2021; accepted 29 July 2021)

\section{Introduction}

Coronavirus disease 2019 (COVID-19) is causing worldwide morbidity and mortality. The aetiology and progression of the - initially - respiratory disease in those severely affected is complex and affects many organ systems. Disease severity varies widely between affected individuals, from an asymptomatic course or mild symptoms to an overwhelming multisystem illness with high mortality. Those who are older, obese and with major pre-existing health conditions (including cardiovascular disease and diabetes) are at greatest risk ${ }^{(1-5)}$. In addition to a high incidence of acute respiratory distress syndrome (ARDS), the virus poses particular risks of both arterial and venous thromboembolism and of haemorrhagic complications: pulmonary embolism and stroke are important causes of death. Endothelial damage may also contribute to the high incidence of acute kidney injury (AKI). Immune dysfunction underlies the catastrophic 'cytokine storm' which can be a terminal event $^{(1,4,6)}$. Several therapeutic interventions, particularly those that control cytokine production, have recently been shown to reduce mortality in patients with a severe disease course ${ }^{(4,7-9)}$. Vaccination programmes are currently rolled out globally.
Until the time that a large proportion of the world population has acquired immunity, infection prevention and reduction of disease severity is paramount, in view of the severe disease process with long rehabilitation time in many patients ${ }^{(10)}$.

Vitamin D has received increased interest since it is known to modulate immune function and the inflammatory response and vitamin D deficiency is associated with increased risk of respiratory infections ${ }^{(10-15)}$ and adverse health outcomes in severely ill patients ${ }^{(16,17)}$. It may therefore be involved in both susceptibility and progression of respiratory disease. No good-quality, population representative data on the relationship between vitamin $\mathrm{D}$ status and severe acute respiratory syndrome coronavirus 2 (SARS-CoV-2) infection risk and severity of COVID-19 exist. The first findings from three intervention studies in hospitalised COVID-19 patients supplemented with vitamin D were recently published ${ }^{(18-20)}$, and several randomised controlled trials (RCT) in diverse population or patient groups are ongoing ${ }^{(10,21,22)}$.

Vitamin D status is measured as the plasma concentration of 25-hydroxy vitamin D (25(OH)D). Deficiency thresholds for population health are defined as $25(\mathrm{OH}) \mathrm{D}$ serum concentrations $<25$ or $30 \mathrm{nmol} / \mathrm{L}$ per UK and US guidelines. Thresholds or target

Abbreviations: 25(OH)D, 25-hydroxy vitamin D; 1, 25(OH) 2 D, 1, 25-dihydroxy vitamin D; 24, 25(OH) 2 D, 24, 25-dihydroxy vitamin D; PTH, parathyroid hormone; IGF-1, insulin growth factor 1; FGF23, fibroblast growth factor 23; DBP, vitamin D binding protein.

Corresponding author: Inez Schoenmakers, email I.Schoenmakers@uea.ac.uk 
values for $25(\mathrm{OH}) \mathrm{D}$ may be set higher for clinical management and specific patient groups ${ }^{(23-25)}$. Vitamin D status has been shown to be associated with many health outcomes, but for many chronic diseases other than musculoskeletal health, intervention trials are less consistent and often do not confirm findings of observational studies ${ }^{(26-28)}$. This can potentially be ascribed partly to the confounding effects of vitamin D supply from sources other than the intervention given in RCTs (i.e. vitamin D supply through cutaneous sun exposure and from food and supplements), vitamin D uptake in and potential mobilisation from bodily stores and the complex nature of vitamin D metabolism. Vitamin D status is therefore influenced by factors associated with lifestyle and fitness. In addition, status is affected by pathological changes occurring during acute and chronic illness. Therefore, causality and reverse causality are difficult to distinguish. Further, the effect of interventions may depend on baseline and post-supplementation vitamin D status, but also results considering $25(\mathrm{OH}) \mathrm{D}$ before and after supplementation are conflicting ${ }^{(29-32)}$.

The role of vitamin D and the effect of supplementation has also been investigated in studies and intervention trials with respiratory disease outcomes and critically ill patients. These are likely relevant for the current COVID-19 epidemic.

Here we summarise recent findings regarding vitamin D status and metabolism in patients, with a particular focus on those severely ill and with COVID-19. The effect of vitamin D supplementation on respiratory disease and critically ill patients is described in the context of alterations of vitamin D metabolism and requirements with severe illness. We also provide an overview of guidelines to correct and maintain vitamin D status for specific categories of patients and the prevention of vitamin D deficiency in population groups.

\section{COVID-19, vitamin D status and supplementation}

The recent COVID-19 epidemic identified a high prevalence of vitamin D deficiency amongst patients ${ }^{(33)}$, particularly those that develop severe symptoms of the disease ${ }^{(34-39)}$. Vitamin D deficiency $(25(\mathrm{OH}) \mathrm{D}<30 \mathrm{nmol} / \mathrm{L})$ at hospital admission $(n=185)$ was associated with increased hazard ratio to require invasive mechanical ventilation and death in one study ${ }^{(40)}$, but this was not found in another, slightly smaller study $(n=109)^{(41)}$. Patients at increased risk of requiring intensive care unit (ICU) admission and ventilation appear to be carriers of common risk factors for vitamin D deficiency, that is, being overweight or obese, having type 2 diabetes, hypertension and chronic kidney disease ${ }^{(2,3,36,42)}$, but vitamin $\mathrm{D}$ status has also been reported to be an independent predictor after adjustment for confounding factors ${ }^{(37,40)}$. This raises the question whether vitamin $\mathrm{D}$ deficiency is a risk factor for this viral infection and/or developing severe disease symptoms is a biomarker of poorer health or that the disease process is associated with a decrease in vitamin D status as outlined below. In several countries (the United States and UK), overrepresentation of ethnic minorities testing positive and/or developing severe symptoms is reported ${ }^{(3,39,43-46)}$ (https:// digital.nhs.uk/coronavirus/coronavirus-data-services-updates/ ethnicity-and-outcomes-of-covid-19-patients-in-england). The higher prevalence of severe illness in specific ethnic minority groups in the United States and UK, countries with temperate climates, has been suggested to be related to their generally lower vitamin D status, due to lower rate of cutaneous vitamin D production associated with a darker skin tone. Many other factors may also play a role, including higher risk of obesity, hypertension, type 2 diabetes mellitus, elevated inflammation markers and renal impairment, in these groups ${ }^{(47)}$. Individuals of specific racial descent may potentially also have different responses to infection and treatment and may require different treatment strategies. In addition, overrepresentation of these groups in professions with high exposure risk, differences in access to and use of health care systems and other socio-economic factors may play a key role in some areas ${ }^{(45,48)}$. Country differences in the prevalence of COVID-19 between ethnic groups may also reflect differences in population diversity and characteristics and health care systems. There are no prospective data available that directly allow the investigation of the protective role of vitamin D status, intake and supplementation in the prevention of infection with SARS-CoV-2 at the time of viral exposure and subsequent development of COVID-19 symptoms. Two studies with retrospective data from the population-based UK BIOBANK showed that plasma 25(OH)D measured 10-14 years before the COVID-19 outbreak was not associated with the risk of developing moderate-to-severe symptoms of the disease after correction for appropriate confounders ${ }^{(44,49,50)}$. In univariate models, Hastie ${ }^{(50)}$, but not Raisi- Estabragh found an increased odds ratio of COVID positivity with lower plasma concentrations of $25(\mathrm{OH}) \mathrm{D}$, but this did not remain significant after correction for range of confounders (BMI, age, ethnicity and season) and co-morbidities. Other retrospective studies used large data sets from clinical laboratories and medical records. Kaufman et al. $^{(46)}$ reported a significant negative association between the percentage of patients testing positive for SARS-CoV-2 and season-corrected plasma $25(\mathrm{OH}) \mathrm{D}$ measured within a year prior to SARS-CoV-2 infection. In subgroup analyses, Kaufman presented data by ethnic group (as based on predominance of ethnicity by postcode area), showing (a) a higher COVID positive incidence rate and (b) a lower plasma 25(OH)D concentration in postcodes with predominantly Black and Hispanic communities compared with predominantly white communities, but (c) the association with $25(\mathrm{OH}) \mathrm{D}$ was negative and significant in all three groups. Meltzer conducted two retrospective studies using large data sets from clinical laboratories and medical records. They included individuals who had a COVID-19 PCR test following potential COVID-19 symptoms or exposure and if assessed for vitamin $\mathrm{D}$ status within 1 year before the COVID test. In the 2020 study by Meltzer ${ }^{(51)}$, this was based on plasma $25(\mathrm{OH}) \mathrm{D}$ or $1,25(\mathrm{OH})_{2} \mathrm{D}$ concentrations. In the larger ( $n=4638), 2021$ study, this was based on $25(\mathrm{OH}) \mathrm{D}$ only ${ }^{(39,51)}$. An increased risk of testing positive with lower category of vitamin D status (values below versus above $50 \mathrm{nmol} / \mathrm{L}^{(51)}$ and below $50 \mathrm{nmol} / \mathrm{L}$ versus $\geq 100 \mathrm{nmol} / \mathrm{L}^{(39)}$ ) was reported in both studies. In subgroup analyses by ethnicity and controlling for a range of confounders and co-morbidities as well as time since last 25(OH)D test, Meltzer ${ }^{(39)}$ reported an increased risk of infection (incidence rate ratio (IRR) $2 \cdot 55$; $95 \%$ CI, 1.26-5.15) in African Americans with a 25(OH)D below $50 \mathrm{nmol}$ compared with those with a concentration over $100 \mathrm{nmol} / \mathrm{L}$ ( $<20$ versus $>40 \mathrm{ng} / \mathrm{mL}$ ). 
The relationship between the COVID-19 IRR and 25(OH)D was non-linear and non-significant for the category $50-75 \mathrm{nmol} / \mathrm{L}$ compared with $\geq 100 \mathrm{nmol} / \mathrm{L}$. This association with $25(\mathrm{OH}) \mathrm{D}$ was not found in white counterparts. The results from Kaufman and Meltzer suggest that there may be an interaction between ethnicity, vitamin D status and COVID-19 risk. However, differences between ethnic groups in the relative risk of infection and association with vitamin D status may also be determined by other factors that differ by ethnicity as outlined above. Such associations between COVID infection risk and vitamin D status may be lost in those reports that applied statistical adjustment for ethnicity ${ }^{(50)}$, since in temperate climates, vitamin D status differs by ethnic group. Another study (Israel; subtropical region) reported an increased odds ratio for infection and hospitalisation with COVID-19 amongst patients who had a plasma 25(OH)D below $75 \mathrm{nmol} / \mathrm{L}$ tested before the COVID19 outbreak $^{(52)}$. In this study, it was unclear how long before the outbreak and in which season this prior test of $25(\mathrm{OH}) \mathrm{D}$ was done. Both Kaufman and Merzon ${ }^{(46,52)}$ did not correct for body composition nor provide data whether treatment of vitamin D deficiency was initiated after testing, a factor considered in the two studies by Meltzer ${ }^{(39,51)}$.

There are several limitations to these prospective populationbased studies and the use of medical records. Changes in recommendations for vitamin D intake and testing for and correction of deficiency may have resulted in secular trends in population vitamin D status. In the UK, however, population vitamin D status did not substantially change after the 2016 revised guidance (https://www.gov.uk/government/collections/national-dietand-nutrition-survey). Although vitamin D status is known to track within a person, it is strongly influenced by season. In temperate climates, like the UK, population vitamin D status typically cycles with the seasons, with a nadir in March and a peak in September ${ }^{(53)}$. The nadir thus coincides with the peak of many respiratory viral infections, but also other factors play a role, including meteorological factors (temperature, UV index, humidity) influencing virus survival and time spent indoors ${ }^{(54,55)}$. It may therefore be reasonable to assume that vitamin D status at the time of viral exposure may be the more relevant measure than a year average or season-adjusted value. Another study, relating the severity of the COVID outbreak with latitude and season also suggested a role of vitamin D status ${ }^{(56,57)}$. However, the subsequent spread of the virus across all climate zones and the resurge of COVID prevalence in September 2020 and summer 2021 at northern temperate latitudes does not appear to strongly support this hypothesis. Data from population studies, such as the Biobank studies ${ }^{(44,49,50)}$, are further limited by the fact that those typically at increased risk of being exposed or developing severe COVID-19 symptoms (i.e. ethnic minority groups and older frail people) are often underrepresented in population surveys ${ }^{(45,48)}$, while in data sets based on medical records, individuals with underlying health conditions may be overrepresented. In addition, in clinical data sets that are restricted to patients with a prior biochemical test of $25(\mathrm{OH})$ $\mathrm{D}$, individuals with an increased risk of deficiency and receiving treatment are expected to be overrepresented. Changes in vitamin D status following testing and treatment also need to be considered. Notwithstanding, generating 'optimal' data to assess the protective role of vitamin D status would require near-impossible intense surveillance and sampling of large cohorts of people potentially acquiring the infection.

Findings of the first small, open-label vitamin D intervention trial ( $n=50$ intervention; $n=26$ control group) with hospitalised COVID-19 patients in Spain (diagnosed by positive PCR test and radiographic evidence of viral pneumonia) was recently published ${ }^{(18)}$. In this study, which was a sub-study COVIDIOL cohort, an intermediate high oral dose of calcifediol (the pharmaceutical form of $25(\mathrm{OH}) \mathrm{D}$ ) at hospitalisation and at regular intervals thereafter was provided. The control group received standard medical care without vitamin D. In the vitamin D group, the risk of ICU admission was significantly reduced (OR 0.02; 95\% CI 0.002-0.17), but this was based on one patient in the intervention group and thirteen in the control group requiring ICU treatment. In this study, a range of prognostic indices and risk factors for the development of severe symptoms were investigated. Compared with the intervention group, there was a higher prevalence of potential risk factors for the development of severe COVID in the control group (hypertension: $24 \%$ versus $58 \%, P=0.002$; diabetes mellitus $6 \%$ versus $19 \% ; P=0.08$ ). After correction for these potential confounding factors, differences in the OR remained significant (OR 0.03; 95\% CI 0.003-0.25). Baseline and post-supplementation vitamin D status was not assessed, and potential confounding by body composition was not considered. Differences in deaths were also investigated and were not significant. However, interpretation of this outcome was hindered by the design the study, by which supplementation was stopped on admission to ICU. Nogues ${ }^{(20)}$ reported a second sub-study from the COVIDIOL cohort including a larger data set $(n=447$ intervention; $n=391$ control group). Interventions were identical, but in this sub-study, supplementation was continued after ICU admission. Baseline 25(OH)D was 32.5 (IQR 20-55) nmol/L. Co-morbidities were well balanced, except for a slightly lower baseline 25(OH)D concentration in the control group. This study also showed a reduced risk of ICU admission with and without adjustments for confounders, which included baseline 25(OH)D (confounder adjusted OR $0 \cdot 13 ; 95 \%$ CI $0 \cdot 07-0 \cdot 23$ ). Mortality was significantly reduced in the calcifediol-supplemented group (confounder-adjusted OR 0.21; 95\% CI 0·10-0.43). A randomised placebo-controlled vitamin D intervention trial in Brazil ( $n=120$ intervention; $n=120$ placebo) with hospitalised COVID-19 patients (diagnosed by positive PCR test) administered a single dose of 200,000 IU D $31.4 \mathrm{~d}$ after admission and $10 \cdot 3 \mathrm{~d}$ after onset of symptoms. Mean baseline $25(\mathrm{OH}) \mathrm{D}$ was $52 \pm 9 \cdot 1 \mathrm{nmol} / \mathrm{L}$. This trial did not result in a reduction in length of hospitalisation, inhospital mortality, risk of ICU admission or requiring mechanical ventilation $^{(19)}$. Rastogi ${ }^{(58)}$ investigated the 21-d SARS-CoV-2 clearance rate in mildly symptomatic or asymptomatic individuals with a $25(\mathrm{OH}) \mathrm{D}<50 \mathrm{nmol} / \mathrm{L}$ (median baseline concentration $<25 \mathrm{nmol} / \mathrm{L})$. Supplementation was open label and individually tailored to achieve a $25(\mathrm{OH})$ concentration over $50 \mathrm{nmol} / \mathrm{L}$. They reported a higher proportion of patients who were SARS-CoV-2 negative after $21 \mathrm{~d}$ in the supplemented group ( $n=10$ of $16 ; 62.5 \%$ ) versus the placebo group ( $n=5$ of $24 ; 20 \cdot 8$ $\%$, although the mean duration to being SARS-CoV-2 negative was not different between groups. No data were presented on 
the severity of symptoms or length of hospitalisation, and no data on risk factors.

Time from onset of COID symptoms was only reported in the study by Murai $(10 \cdot 3 \pm 4.3 \mathrm{~d})$; Nogues ${ }^{(20)}$, Entrenas Castillo ${ }^{(18)}$ and Murai ${ }^{(19)}$ reported time from hospitalisation to supplementation ( 0,0 and $1.4(0.9 \mathrm{~d}) \mathrm{d}$, respectively). Considering the potential multifactorial role of vitamin $\mathrm{D}$ (and thus status and supplementation) in different stages and aspects of the response to viral infection and subsequent development of symptoms, time since infection and development of (severe) symptoms relative to the start of supplementation as well as baseline 25(OH)D concentrations may be important factors to consider in the evaluation of the effect of interventions. This is supported by secondary outcomes reported by Nogues ${ }^{(20)}$. They found that, when mortality rates were considered including both patients that initiated calcifediol treatment at hospitalisation $(n=447)$ and those that first received this at ICU admission $(n=53)$, the adjusted mortality OR (0.52; $95 \%$ CI 0.27-0.99) was higher than when only patients were considered that initiated treatment at admission. The authors speculated that supplementation is more effective if initiated before the development of ARDS.

Though not randomised, an audit of standard care in a French nursing home found that residents who had received regular 2-3 monthly vitamin D supplementation (oral 80,000 IU as a bolus) within 1 month before or 1 week after SARS$\mathrm{CoV}-2$ virus infection had a less severe disease course and lower mortality ${ }^{(59)}$. Similarly, an audit of vitamin D supplementation in frail hospitalised COVID-19 patients, showed a lower mortality risk in those that who had received regular vitamin D supplementation preceding infection and in those supplemented directly after testing positive (both 80,000-100,000 IU as a bolus) compared with those who did not receive vitamin D supplementation ${ }^{(60)}$

\section{Upper respiratory tract infections and vitamin D status and supplementation}

Observational studies have shown that vitamin D deficiency may predispose to increased risk of viral acute respiratory tract infections. Findings of the effect of vitamin D supplementation on the risk of preventing acute respiratory tract infections are conflicting. Meta-analyses of RCTs and recent RCTs indicate that daily supplementation (intakes of 400-1000 IU/d) has a small protective effect ${ }^{(10,11,14,15,61)}$. No protective effect was found with less frequent (weekly or less or after a bolus) administration. Many of the studies were conducted in populations with pre-existing respiratory diseases and in children. The most recent and largest meta-analyses found no interaction with $25(\mathrm{OH}) \mathrm{D}$ concentration at baseline ${ }^{(61)}$, whereas in an earlier individual participant data meta-analyses, a stronger protective effect was found in subgroups with baseline vitamin D deficiency $(<25 \mathrm{nmol} / \mathrm{L})^{(11,62)}$. The two UK Scientific Advisory Committee on Nutrition (SACN) rapid reviews on vitamin D and acute respiratory tract infections concluded that there is evidence of a small beneficial effect of vitamin D supplementation with intakes of 400-1000 IU/d, but that sufficient evidence is only available for children 1-16 years of age (https://www.gov.uk/ government/publications/sacn-rapid-review-vitamin-d-and- acute-respiratory-tract-infections). A recent study in long-term care residents, with approximately one-third of participants with a baseline $25(\mathrm{OH}) \mathrm{D}<50 \mathrm{nmol} / \mathrm{L}$, showed a significant protective effect (odds ratio 0.67 ) with high-dose monthly supplementation (100,000 IU per month). However, in this study, consistent with other reports with high-dose bolus vitamin D supplementation, an increased risk of falling was observed ${ }^{(13)}$.

Evidence from a large multi-centre observational study in infants hospitalised for bronchiolitis suggests that vitamin D status is associated with severity of respiratory disease. This study showed that the percentage of hospitalised children that proceeded to need intensive care treatment was almost twice as high in those with a $25(\mathrm{OH}) \mathrm{D}<50 \mathrm{nmol} / \mathrm{L}$ compared with those with a concentration $>75 \mathrm{nmol} / \mathrm{L}(22 \% \text { versus } 12 \%)^{(63)}$. Vitamin D intervention studies in children with pneumonia have, however, not shown a reduction of length of recovery and other disease outcomes ${ }^{(63)}$.

Mechanistic studies support a role of vitamin D and its metabolites and vitamin D binding protein (DBP) in immune function and pulmonary health, which is summarised below. The contrasting findings between observational, mechanistic and intervention studies suggest that many other factors play a role; the beneficial effects of vitamin D may be limited to specific subgroups, the alterations in vitamin $\mathrm{D}$ metabolism with disease processes may influence its function and/or other drivers of the immune and inflammatory response may be predominant, particularly in severe illness.

\section{Summary of interactions of vitamin D metabolites and vitamin $D$ binding protein with respiratory tract infections and immune function}

The effect of vitamin D and DBP on immune function and pulmonary health has been described in in vitro, ex vivo and animal models and in human health ${ }^{(64)}$. It is considered to be multi-factorial and involves both the innate and adaptive immune function (see reviews ${ }^{(10,64,65)}$ ). Laboratory studies indicate that the active metabolite 1,25 -dihydroxy vitamin $\mathrm{D}\left(1,25(\mathrm{OH})_{2} \mathrm{D}\right)$ modulates the expression of angiotensin-converting enzyme 2 (ACE2), the receptor for SARS-CoV, including SARS-CoV-2, and may thus modulate viral entry and infection ${ }^{(10,56)}$. To date, it is unclear what the importance of this mechanism is. Vitamin D metabolites and DBP appear to play an important role in the immune and inflammatory response and, hence, disease severity and the development of immunity. It may also be hypothesised that vitamin D status modulates the response to vaccination. Many of the cells of the immune system and those with a barrier function, express vitamin D receptors (VDRs) and CYP27B1, the enzyme that hydroxylates $25(\mathrm{OH}) \mathrm{D}$ into $1,25(\mathrm{OH})_{2} \mathrm{D}$. This locally produced $1,25(\mathrm{OH})_{2} \mathrm{D}$ activates VDRs for autocrine and paracrine functions. It stimulates the expression of the antimicrobial function of cathelicidin, which modulates the chemokine and cytokine response and stimulates the chemotaxis of neutrophils, monocytes and T cells, thus promoting the clearance of respiratory pathogens ${ }^{(10,64-66)}$. Further, $25(\mathrm{OH}) \mathrm{D}$ and $1,25(\mathrm{OH})_{2} \mathrm{D}$ stimulate autophagic encapsulation of viral particles, promoting lysosomal degradation and antigen presentation $^{(65)}$. The role of vitamin D deficiency and 
supplementation in lymphocyte differentiation and apoptosis remains unclear ${ }^{(67,68)}$, but considering that severe illness with COVID-19 is characterised by inadequate T-cell responses ${ }^{(1,69)}$, it may be expected that the effects of vitamin D metabolites on immune function with severe COVID are altered. It may therefore be speculated that vitamin D status is of particular importance in earlier stages and the progression of the disease, preventing the development of a cytokine storm, found in patients with a severe disease course of COVID-19 ${ }^{(10,64)}$. Vitamin D deficiency has also have been linked to increased risk of the development of endothelial dysfunction and cardiovascular complications, frequently observed in patients hospitalised with COVID-19. Although no direct casual evidence is available, mechanistic studies suggest that deficiency or reduced VDR activation leads to overexpression of the renin- angiotensin aldosterone system (RAAS), hypertension and increased thrombogenicity ${ }^{(65)}$. This may influence the effects SARS-CoV-2 infection and its interaction with the ACE2 receptor, suggested to lead to dysregulation of RAAS ${ }^{(65,70)}$.

\section{Summary of vitamin D metabolism}

\section{Vitamin D metabolism}

Vitamin D is synthesised in the skin after sunshine exposure and taken up into the lymph system. In temperate climates this only occurs during spring and summer months, whereas at latitudes $<30^{\circ}$ north and south this can take place throughout the year. Oral vitamin D is rapidly and efficiently absorbed from the intestine incorporated in chylomicrons. Vitamin D from both supply routes is transported to the liver, but part of it may be taken up by fat tissue. In the liver, vitamin D is converted to $25(\mathrm{OH}) \mathrm{D}$ (Fig. 1). Despite the efficient conversion ( $~ 80 \%$ at first passage with normal liver function), it takes several days to weeks to correct vitamin D deficiency unless high (bolus) dosages are given, particularly in severely deficient patients with a high BMI. This is thought to be due to the uptake of vitamin $\mathrm{D}$ by fat cells. Oral supplementation with $25(\mathrm{OH}) \mathrm{D}$ (i.e. calcifediol), at present only available on prescription, leads to a faster (with an increase already detectable within a few hours after administration) and proportionally higher increase in plasma $25(\mathrm{OH}) \mathrm{D}^{(71)}$.

A further conversion into the active metabolite $1,25(\mathrm{OH})_{2} \mathrm{D}$ is required, and this occurs in the kidney for systemic effects. Local conversion takes place in many other tissues for autocrine and paracrine effects, including the lung and cells of the immune system. The regulation of $1,25(\mathrm{OH})_{2} \mathrm{D}$ production in the kidney is predominantly under control of parathyroid hormone (PTH), $1,25(\mathrm{OH})_{2} \mathrm{D}$ itself, fibroblast growth factor 23 (FGF23) and several other factors, including sex hormones (reviewed in Ref. ${ }^{(71)}$ ). The extra-renal production is not under the control of these factors, except for FGF23. Instead, its regulation is thought to be tissue specific and is only partly understood. In immune cells, the regulation of $1,25(\mathrm{OH})_{2} \mathrm{D}$ production is partly influenced by inflammatory factors and cytokines (reviewed in Refs. ${ }^{(10,64,72)}$ ) (Fig. 1).

Generally, there is no or a poor correlation between plasma concentrations of $25(\mathrm{OH}) \mathrm{D}$ and $1,25(\mathrm{OH})_{2} \mathrm{D}$. The concentration below which $25(\mathrm{OH}) \mathrm{D}$ becomes rate limiting for $1,25(\mathrm{OH})_{2} \mathrm{D}$ production is not well established and also depends on other factors. It is generally assumed that when $25(\mathrm{OH}) \mathrm{D}$ falls below $15 \mathrm{nmol} / \mathrm{L}$, plasma $1,25(\mathrm{OH})_{2} \mathrm{D}$ is reduced ${ }^{(71)}$. A meta-analysis of supplementation studies, however, showed that post-supplementation $1,25(\mathrm{OH})_{2} \mathrm{D}$ concentrations also increased when baseline $25(\mathrm{OH}) \mathrm{D}$ concentrations were above $15-20 \mathrm{nmol} /$ $\mathrm{L}^{(73)}$. It is unclear whether at lower $25(\mathrm{OH}) \mathrm{D}$ concentrations the balance between renal and extra-renal $25(\mathrm{OH}) \mathrm{D}$ availability and tissue uptake is altered. In the kidney, internalisation of $25(\mathrm{OH}) \mathrm{D}$, bound to its binding protein is through an active megalin-cubilin receptor mediated mechanism. It may therefore be assumed that renal uptake takes place against the concentration gradient, partly overcoming the effects of low plasma $25(\mathrm{OH}) \mathrm{D}$ availability. In most other tissues, including those pertaining to the immune system, a receptor-mediated internalisation mechanism has not been demonstrated. According to the free hormone theory, cellular uptake in these extra-renal tissues is thought to be concentration dependent and thus is reduced when $25(\mathrm{OH}) \mathrm{D}$ is low (see further below).

\section{The role of vitamin $D$ binding protein in vitamin $D$ metabolism}

The majority of vitamin D and its metabolites circulate in plasma bound to DBP ( $~ 85-90 \%$ ) and to a lesser extent and with a lower binding affinity to albumin. Less than $1 \%$ circulates in its free form $^{(71)}$. In healthy people, the free $25(\mathrm{OH}) \mathrm{D}$ concentration is highly correlated to total $25(\mathrm{OH}) \mathrm{D}$ and accordingly, the free: total $25(\mathrm{OH}) \mathrm{D}$ ratio is stable throughout the physiological ranges of $25(\mathrm{OH}) \mathrm{D}^{(74)}$. In some physiological and pathological conditions, the free $25(\mathrm{OH}) \mathrm{D}$ fraction is altered, and this is thought to be predominantly a result of changes in the concentrations of $\mathrm{DBP}^{(74)}$. $\mathrm{DBP}$ binding of vitamin $\mathrm{D}$ metabolites has several functions: to prolong half-life and to facilitate cellular internalisation of vitamin D metabolites through the megalin-cubilin receptor pathway. The megalin-cubilin receptor is expressed in a number of other tissues and is not specific to the DBP-vitamin D complex. Internalisation of vitamin D metabolites through this pathway has to date only been shown in renal and muscle tissue and potentially in the mammary gland. Other tissues, including those pertaining to the immune system are thought to be mostly dependent on the internalisation of the free fraction. However, other internalisation mechanisms for $25(\mathrm{OH}) \mathrm{D}$ and $1,25(\mathrm{OH})_{2} \mathrm{D}$ have been proposed, and DBP also plays an important role in the delivery and distribution of compounds to all tissues ${ }^{(75)}$.

The megalin-cubilin mediated internalisation of the DBP$25(\mathrm{OH}) \mathrm{D}$ complex is thought to be the predominant internalisation route in the kidney and is also essential for renal reabsorption of the DBP complex and thus prevents urinary losses of both the protein and the associated vitamin D metabolites. A decrease in the expression of these receptors with renal impairment is associated with a decline in systemic $1,25(\mathrm{OH})_{2} \mathrm{D}$ concentrations. It may be speculated that also a reduction of plasma DBP may lead to a reduction in renal bioavailability of vitamin D metabolites, reducing the substrate for production of systemic $1,25(\mathrm{OH})_{2} \mathrm{D}$.

DBP binding protects against catabolism of vitamin D metabolites. As a consequence, in conditions with a decreased DBP 


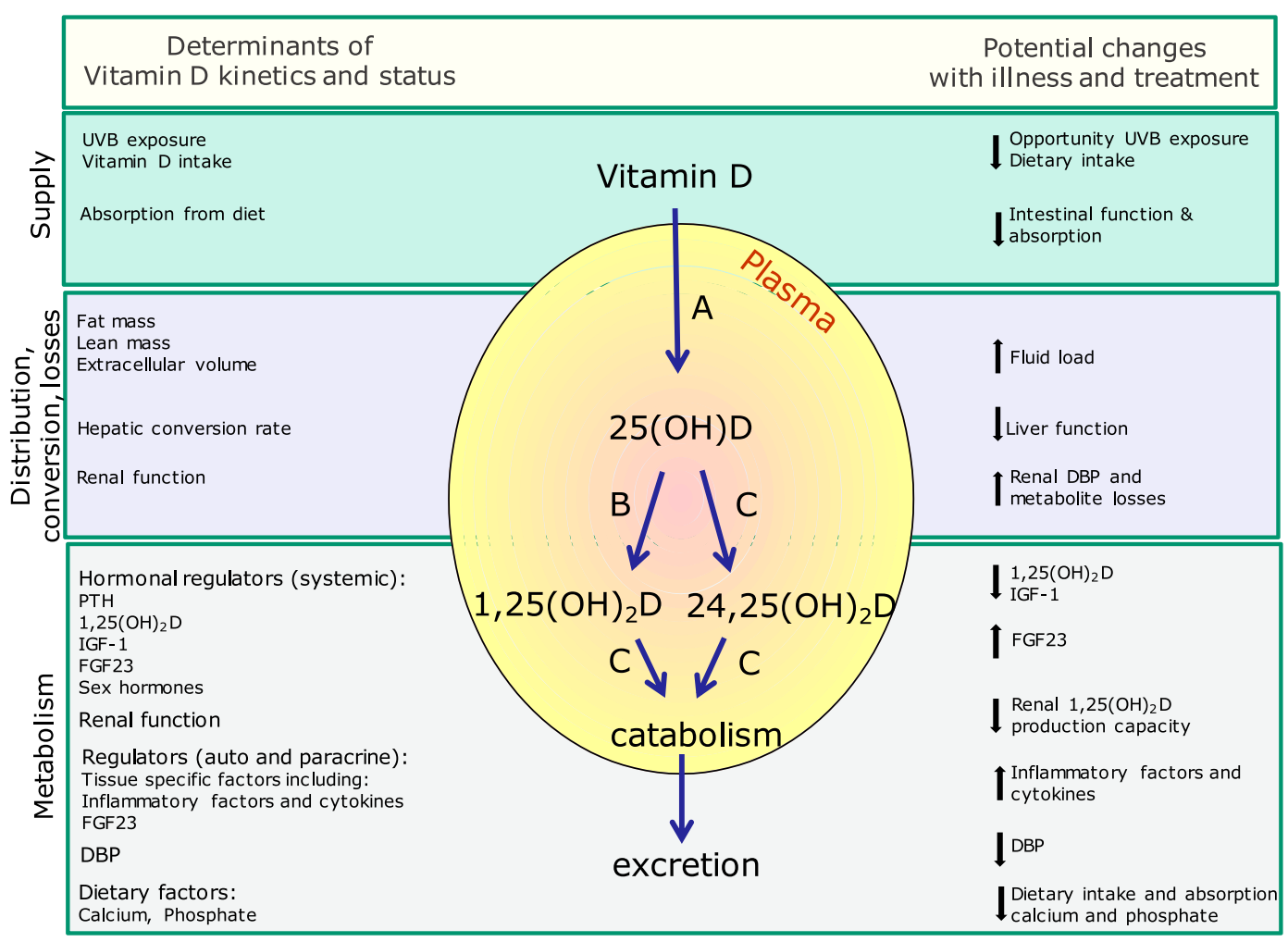

Fig. 1. Determinants of the kinetics of vitamin $D$ and potential changes with severe illness and treatment. Blue arrows indicate metabolic pathways of vitamin $D$ and vitamin D metabolites. Letters indicate hydroxylation enzymes: A, CYP2R1; B, CYP27B1; C, CYP24A1. Changes associated with severe illness lead to pronounced changes in supply, distribution, hepatic conversion, renal losses and metabolism due to changes in hydroxylation enzyme activity. Determinants of these changes are summarised. Conversion (A) of vitamin D into 25(OH)D may be impaired, activation (B) of $25(\mathrm{OH}) \mathrm{D}$ into $1,25(\mathrm{OH})_{2} \mathrm{D}$ may be decreased, and catabolism $(\mathrm{C})$ of $25(\mathrm{OH}) \mathrm{D}$ into $24,25(\mathrm{OH})_{2} \mathrm{D}$ and $1,25(\mathrm{OH})_{2} \mathrm{D}$ into1,24,25(OH $)_{3} \mathrm{D}$ and further downstream products may be increased. Metabolism may further be influenced by medication use. For further explanation, see text. Vitamin $\mathrm{D}$ metabolism is further influenced by physiological factors and life stage, including growth, pregnancy and ageing

concentration, although this has never been measured directly, it is expected that the bodily stores of $25(\mathrm{OH}) \mathrm{D}$ are more rapidly depleted and that the half-life of $25(\mathrm{OH}) \mathrm{D}$ and the active metabolite $1,25(\mathrm{OH})_{2} \mathrm{D}$ decreases. This potentially explains the decrease in vitamin D status during acute illness and the frequently observed poor vitamin D status in ICU patients, even in those who do not have the traditional risk factors and may have adequate vitamin $\mathrm{D}$ intake. These mechanisms may also partly explain the low and decline in $1,25(\mathrm{OH})_{2} \mathrm{D}$ concentrations observed in many ICU patients as described in the next sections.

DBP further fulfils several other functions in the immune system and in response to inflammation and tissue damage as summarised below ${ }^{(71,75,76)}$.

\section{Regulation of the concentration and production of vitamin $D$ binding protein}

Vitamin D binding protein is mainly produced in the liver, although the gene and protein are also expressed in very low concentrations in other tissues, including monocytes ${ }^{(77)}$. It has three domains. The 'A' domain binds vitamin D metabolites and the $\mathrm{B}$ and $\mathrm{C}$ domains actin, and this can occur simultaneously ${ }^{(76)}$. The estimated daily production of DBP is about 700 $900 \mathrm{mg} / \mathrm{d}$ for an adult $(10 \mathrm{mg} / \mathrm{kg} / \mathrm{d})$. The plasma concentration of DBP in healthy people is in the micromolar range $(\sim 6 \mu \mathrm{mol} / \mathrm{L}$ or $300 \mathrm{mg} / \mathrm{L}$ ) and is remarkably stable throughout the life course.
After acute depletion, for example after trauma or plasma exchange, DBP returns to baseline values after several days ${ }^{(78)}$. Reported mean plasma concentrations in healthy populations vary between 200 and $600 \mathrm{mg} / \mathrm{L}$. These differences are probably mostly related to assay differences and lack of standardisation. Some (monoclonal) assays report lower values for specific population groups due to their incomplete quantitation of specific genotypes of $\mathrm{DBP}^{(79)}$.

Similar to albumin, $40 \%$ of DBP is intravascular and $60 \%$ is distributed in the interstitial space of various organs (primarily muscle, adipose tissue, connective tissue and skin). It is also present in bronchoalveolar, amniotic, cerebral and seminal fluid, breast milk and saliva and bound to the cell surface of many cell types, including neutrophils ${ }^{(76,77,80)}$.

In humans, exposure to oestrogens increases serum DBP, but androgens have no effects. Vitamin D status (including deficiency and excess) and supplementation have no effect on serum DBP concentration. In vitro models showed that dexamethasone, interleukine-6 (IL-6) and tumour necrosis factor alpha (TNF $\alpha$ ) stimulate, while transforming growth factor beta (TGF $\beta$ ) inhibits its production ${ }^{(81)}$. Accordingly, DBP hepatic production was reported to increase in trauma patients ${ }^{(82)}$. Although acute inflammation decreases plasma DBP concentrations, in states of chronic low-grade inflammation such as in obesity and rheumatoid arthritis, comparable or slightly higher DBP concentrations are reported, suggesting that increased hepatic 
production compensates for the potential higher degradation rate of DBP.

Decreased serum DBP concentrations are found in patients with liver cirrhosis, with protein-energy restriction and malnutrition, peritoneal dialysis, nephrotic syndrome and a variety of other kidney diseases with proteinuria and renal loss of $\mathrm{DBP}^{(74,76,83,84)}$. Plasma DBP is also decreased in conditions associated with cell lysis and the release of intracellular actin into the bloodstream such as during infection or trauma ${ }^{(85-87)}$. This decline in DBP reflects its role as actin scavenger protein ${ }^{(76,83,88)}$.

\section{The role of vitamin $D$ binding protein and vitamin $D$ in actin scavenging and coagulation}

Actin is the most abundant intracellular protein in any organism. During tissue injury, actin is released into extracellular fluids. Intra-cellular actin exists in two states: monomeric globular actin (G-actin) or G-actin polymerised into filaments (F-actin) ${ }^{(72)}$. The process of polymerisation and depolymerisation is dynamic and highly regulated by actin binding proteins. When released into the extracellular space, actin escapes normal intracellular regulatory mechanisms and the protein will form F-actin filaments. In animal models, extracellular F-actin filaments have been shown to alter the coagulation and fibrinolytic systems, leading to occlusion and damage of the microcirculation, particularly in the lung ${ }^{(72)}$. Actin scavenging by DBP, together with gelsolin, plays an important role in the clearance of actin from the circulation and the prevention of formation of actin filaments. In addition, DBP, particularly when bound to actin, has a regulatory function in neutrophil chemotaxis and, after conversion to macrophage activating factor, in macrophage activation ${ }^{(10,72)}$. The function of DBP as a neutrophil chemotactic cofactor is modulated by $1,25(\mathrm{OH})_{2} \mathrm{D}-\mathrm{DBP}$ binding ${ }^{(72)}$. Much of the mechanisms are still poorly understood ${ }^{(10,72,77,89)}$.

Upon DBP binding of actin, the complex is rapidly catabolised, decreasing DBP plasma half-life from $1 \cdot 7-3 \mathrm{~d}$ to 30 $\min ^{(76,83,88)}$. Bound vitamin $\mathrm{D}$ metabolites are released, and although they may rapidly re-associate with another DBP molecule, the free fraction of vitamin $\mathrm{D}$ metabolites increases. This may be a beneficial response to infection, increasing the availability of vitamin D metabolites for passive cellular internalisation, which may particularly increase the uptake into extrarenal tissues.

Strategies to improve DBP plasma concentrations in patients through stimulation of endogenous production or intravenous administration have not been tested in humans. Administration of (human) DBP to healthy animals was not associated with toxic effects, except the formation of antibodies against the human form of $\mathrm{DBP}^{(90)}$. In vitro models have, however, shown that exposure to the actin-DBP complex causes inflammation and cell death ${ }^{(91)}$. The safety profile may therefore depend on the presence of actin in the extracellular space. Therefore, caution is warranted with strategies to rapidly and extensively increase the DBP concentration in the presence of extracellular actin as this may increase the inflammatory response $^{(72)}$.
Vitamin D status and metabolism in acute and critically ill patients

Vitamin D deficiency is commonly found in critically ill patients of all ages ${ }^{(63,85,87,92-96)}$ and is associated with increased mortality and morbidity ${ }^{(16,17)}$. It is unclear whether vitamin $\mathrm{D}$ deficiency in these patients is a marker of (pre-existing) poor health or low supply prior to hospitalisation (due to limited opportunities for spending time outdoors and/or low dietary intake), or develops as a result of altered metabolism, or whether low tissue availability plays a role in the disease process. In many but not all studies, a decrease in $25(\mathrm{OH}) \mathrm{D}$ is reported over the course of hospitalisation $^{(16,85,87,97-101)}$. Also, a lower plasma $1,25(\mathrm{OH})_{2} \mathrm{D}$ concentration compared with matched controls and a decrease in $1,25(\mathrm{OH})_{2} \mathrm{D}$ is reported in critically ill patients and in patients undergoing major surgery ${ }^{(16,95,97,102-105)}$.

In a longitudinal observational study, Ney ${ }^{(16)}$ showed that preoperative $1,25(\mathrm{OH})_{2} \mathrm{D}$ concentrations in patients undergoing major cardiac surgery was a negative predictor of post-operative organ failure, sepsis, mortality and prolonged hospital stay, whereas pre-operative $25(\mathrm{OH}) \mathrm{D}$ was not predictive. Although the relationship with post-operative $1,25(\mathrm{OH})_{2} \mathrm{D}$ with health outcomes was not reported, pre- and post-operative concentrations seemed to be correlated, and those with low pre-operative values had a further decline in $1,25(\mathrm{OH})_{2} \mathrm{D}$. This parallels findings of a study in ICU patients treated with a high bolus dose of vitamin D. Post-hoc analyses showed that the $1,25(\mathrm{OH})_{2}$ D concentration, not $25(\mathrm{OH}) \mathrm{D}$, measured in plasma $3 \mathrm{~d}$ after vitamin $\mathrm{D}$ administration was predictive of $28-\mathrm{d}$ survival ${ }^{(99)}$. This indicates that renal activation of $25(\mathrm{OH}) \mathrm{D}$ into (systemic) $1,25(\mathrm{OH})_{2} \mathrm{D}$ and maintenance of plasma $1,25(\mathrm{OH})_{2} \mathrm{D}$ concentrations play a key role.

Several mechanisms provide potential explanations (for a summary, see Fig. 1). Renal impairment and AKI are highly prevalent in ICU patients. This is also found in patients with severe COVID-19 symptoms. Renal damage reduces the capacity to convert $25(\mathrm{OH}) \mathrm{D}$ into $1,25(\mathrm{OH})_{2} \mathrm{D}^{(106,107)}$ and leads to renal losses of vitamin D metabolites bound to DBP and albu$\min ^{(87,102)}$. Further, animal models of sepsis show that renal $1,25(\mathrm{OH})_{2} \mathrm{D}$ production may have decreased as a result of decline in insulin growth factor 1 (IGF-1; known to stimulate $1,25(\mathrm{OH})_{2} \mathrm{D}$ production), despite an increase in $\mathrm{PTH}$, commonly observed in sepsis. Catabolism may be expected to be increased due to an increase in FGF23 (known to decrease the half-life of $\left.1,25(\mathrm{OH})_{2} \mathrm{D}\right)$. Finally, the decline in DBP observed with acute and critical illness (see further below) is expected to be associated with an increase in the free fraction and, therefore, catabolism of vitamin D metabolites ${ }^{(71)}$.

An alternative explanation for the decrease in $1,25(\mathrm{OH})_{2} \mathrm{D}$ concentrations is a functional down-regulation of the total concentration to maintain free $1,25(\mathrm{OH})_{2}$ D concentrations constant. This is observed in several studies conducted after surgery, where the free fractions of $25(\mathrm{OH}) \mathrm{D}$ and $1,25(\mathrm{OH})_{2} \mathrm{D}$ remained constant in the presence of a decrease in $\mathrm{DBP}^{(108,109)}$. A longitudinal study in ICU patients, however, showed that the decline in $1,25(\mathrm{OH})_{2} \mathrm{D}$ and $25(\mathrm{OH}) \mathrm{D}$ far exceeded the decline in DBP, rendering the free fractions of these metabolites significantly lower than in healthy controls ${ }^{(105)}$. 
Severe trauma (e.g. hip fracture), major surgical procedures and severe illness (including septic shock, ARDS) lead to pronounced changes in DBP concentrations ${ }^{(85-88)}$. Although not detailed in most reports, this should be assumed to reflect the actin-free DBP concentration, which is measured in most types of assays. Where total DBP is measured, the concentration has been reported to increase ${ }^{(88)}$. In two longitudinal studies in ICU or patients with severe trauma, the total concentration or actin free DBP was shown to initially decrease, while the complexed DBP concentration increased. Subsequently, measured over the course of 7-10 d, actin-free and actin-bound DBP concentrations increased ${ }^{(82,105)}$. Plasma concentrations of DBP (either measured as total, actin-free or actin-bound) are reported to be a sensitive predictor of in-hospital complications, including sepsis and respiratory distress and failure, and of mortality $(72,80,82,88,110-114)$. These data indicate that DBP actin binding capacity and hepatic DBP production in severely ill patients play an important role in survival. It has been hypothesised that, when actin release exceeds DBP scavenging capacity, the formation of actin filaments leads to increased viscosity and increased risk of coagulation ${ }^{(80,86,105)}$. Considering that DBP is also present in alveolar fluids, its involvement in the prevention and development of airway obstructions may be expected $^{(77,80)}$, although the role of DBP and change in DBP concentrations with cell lysis and inflammation in extra-vascular fluids are mostly unknown.

Venous and arterial thromboembolic events are common in ICU patients and those with severe COVID-19, affecting approximately $30 \%$ of cases admitted to intensive care and occurring despite thromboprophylaxis ${ }^{(56)}$. In pre-clinical studies, vitamin D has been shown to have anti-thrombotic effects, and there has been considerable interest in the effects of vitamin D on coagulation, but large intervention studies have failed to show an impact of vitamin D status or supplementation on the risks for thromboembolism or cardiovascular disease ${ }^{(10)}$. This is possibly related to the earlier described reduced capacity to convert $25(\mathrm{OH}) \mathrm{D}$ into $1,25(\mathrm{OH})_{2} \mathrm{D}$ in patients typically at increased risk and depletion of actin scavenging capacity of DBP and gelsolin and the concomitant decrease in plasma albumin concentration, which are not influenced by vitamin $D$ supplementation $^{(106,107)}$

Other aspects of altered metabolism, tissue distribution and extracellular volume also need to be considered in the interpretation of plasma concentrations of vitamin D metabolites, DBP and the potential of receptor activation. Treatment protocols of ICU and surgical patients (e.g. fluid load) may lead to significant haemodilution; the distribution of compounds between the vascular and extra-vascular compartments may be changed; and alterations of tissue uptake and receptor expression may modify sensitivity and changes of circadian rhythms (well known to play an important role in vitamin D metabolism and calcium and phosphate homeostasis ${ }^{(115)}$ ), all of which may lead to pronounced changes in plasma concentrations of any biochemical marker ${ }^{(116-118)}$. All these factors and mechanisms may have implications for the interpretation of findings in ICU patients and potential treatment strategies.
Randomised controlled trials with vitamin D in ICU and acutely ill patients

There is a limited number of published RCTs with administration of native vitamin $\mathrm{D}^{(104,119-125)}$, the pharmaceutical form of $25(\mathrm{OH}) \mathrm{D}$ (calcifediol) or $25(\mathrm{OH}) \mathrm{D}^{(105)}$ or $1,25(\mathrm{OH})_{2} \mathrm{D}^{(126)}$ in critically ill patients. In the majority of studies, vitamin $\mathrm{D}$ or $25(\mathrm{OH}) \mathrm{D}$ was given as either a high bolus or a loading dosage followed by lower maintenance doses. This strategy is chosen when time is critical and has been shown to lead to a rapid correction of vitamin $\mathrm{D}$ deficiency ${ }^{(71,105)}$. These trials were designed (and powered) for different primary and secondary outcomes, and the majority were of small size $(n<100)$ and differed in study population. These trials reported conflicting results. Several meta-analyses were conducted and focused on hard clinical end points. Jointly, meta-analyses of these trials showed no effect on length of hospital or ICU stay and/or requirement for mechanical ventilation ${ }^{(127-130)}$. No effect on mortality (total $28-\mathrm{d}$ or split by mortality in hospital or ICU; mortality after $7 \mathrm{~d}, 28-30$ $\mathrm{d}, 84 \mathrm{~d}$ and 6 months) was reported in three of the meta-analyses $^{(128-130)}$, while Putzu ${ }^{(127)}$ reported a lower odds ratio (0.70 CI: 0.50-0.98) for total mortality (as recorded at the last day of data collection of an individual study) with vitamin D supplementation. The largest, recent multi-centre RCT $(n=1360)^{(123)}$ was only included in the meta-analyses conducted by $\operatorname{Lan}^{(128)}$. This RCT recruited vitamin-D-deficient (defined as $25(\mathrm{OH})$ $\mathrm{D}<50 \mathrm{nmol} / \mathrm{L}$ ) patients at high risk of death or lung injury, and a bolus of vitamin D $\left(540,000 \mathrm{IU} \mathrm{D}_{3}\right)$ was given within 12 $\mathrm{h}$ after ICU admission. This trial found no effect on 28- or 90-d mortality, days on ventilation and length of stay in hospital or other health care facilities, and none of the wide range of other health outcomes and measurements (which included the percentage of patients that developed ARDS) reached statistical significance. The trial, originally designed to recruit 3000 patients, was stopped on the basis of interim analyses predicting no effect of treatment.

Trials varied in form, dosages, frequency and length of administration of vitamin D or its metabolite. The route of administration was oral, intra-venous or intramuscular. Considering the differences in pharmacokinetic profiles and bio-availability as influenced by the form of vitamin D (native or its metabolite(s)), dosage, frequency and length of administration and route of administration (reviewed in Ref. ${ }^{(71)}$ ), this may be expected to have influenced the results of individual trials. The majority of studies administered a bolus or provided vitamin D for a short length of time. Two meta-analyses analysed the influence of factors affecting the pharmacokinetic profiles. In these, no significant interaction was found between outcomes and route, length and dose of $\operatorname{administration}^{(128,130)}$. However, the validity of outcomes reported after more than five times the half-life of either $25(\mathrm{OH}) \mathrm{D}$ or $1,25(\mathrm{OH})_{2} \mathrm{D}$ is questionable $\left(25(\mathrm{OH}) \mathrm{D}:{ }^{\sim} 2-3\right.$ weeks; $1,25(\mathrm{OH})_{2} \mathrm{D}: \sim 5 \mathrm{~h}$ ), unless these were reported as cumulative data. In addition, administration of bolus dosages, although leading to a rapid increase in $25(\mathrm{OH}) \mathrm{D}$, has a disadvantageous pharmacokinetic profile as set out below in the section 'Symptoms and correction of vitamin D deficiency'. Studies designed to initially rapidly correct vitamin D deficiency, 
followed by a maintenance dose schedule, may be more suitable to evaluate the effect of vitamin D administration in ICU patients.

Most of the intervention studies in ICU patients also showed no effect on plasma concentrations of markers of immune function and inflammatory or pro-inflammatory markers such as cathelicidin, interleukin 6 (IL-6), C-reactive protein and procalcitonin, measured $6 \mathrm{~h}$ to $14 \mathrm{~d}$ after (the start of) vitamin D administration $^{(105,119,121,123,131)}$. However, Leaf ${ }^{(126)}$ demonstrated that $1,25(\mathrm{OH})_{2} \mathrm{D}$ administration increased the leucocyte mRNA expression of cathelicidin and interleukin-10 in sepsis patients. Quraishi $^{(120)}$, also in a study with sepsis patients given enteral vitamin D (400,000 IU as a bolus), found an increase in plasma cathelicidin and a decrease in IL-6 after $5 \mathrm{~d}$. This study also reported a range of other inflammation markers (e.g. C-reactive protein, TNF- $\alpha$ and IFN- $\gamma$ ), which were unchanged. This may potentially reflect that, during severe illness, other drivers of inflammation have a predominant effect.

The dose-response to vitamin $\mathrm{D}$ administration in ICU patients is poorly characterised and not formally subjected to meta-analyses. Studies have shown that the response to vitamin $\mathrm{D}$ and $25(\mathrm{OH}) \mathrm{D}$ given both orally and intravenously to ICU patients is blunted compared with healthy people ${ }^{(105)}$. This is likely a result of impaired hepatic conversion, increased renal losses and a more rapid catabolism. In generally healthy older people, vitamin D supplementation at high bolus dosages appears not to have beneficial effects compared with lower daily or weekly dosages, but has a disadvantageous pharmacokinetic profile $^{(71)}$, and it may increase the propensity of falls ${ }^{(132,133)}$ (https://cks.nice.org.uk/topics/vitamin-d-deficiency-in-adultstreatment-prevention and www.endocrinology.org/media/ 3593/nos_vitamin_d_and_bone_-health_in_adults_web.pdf).

In addition, it may increase the risk of hypercalcaemia and hypercalciuria ${ }^{(15)}$. This appears to be a limited issue in ICU patients. Meta-analyses of the occurrence of hypercalcaemia in RCTs in ICU patients showed no increased risk after supplementation with high dosages of vitamin $\mathrm{D}^{(127)}$. Plasma $1,25(\mathrm{OH})_{2} \mathrm{D}$ concentrations increased with supplementation and were well over the normal reference range in some patients $^{(98,104,119,126)}$, but were not associated with hypercalcaemia. This is in line with the observation that hypercalcaemia is relatively uncommon and hypocalcaemia is frequently observed in ICU patients ${ }^{(35,134)}$. A decrease in total calcium is thought to be partly an adaptive response to maintain the biologically active fraction, ionised calcium, constant in the presence of a decrease in plasma binding proteins, the concentrations of which decrease with acute and critical illness. However, also the ionised calcium concentration is often below normal ranges with sepsis and other acute inflammatory illnesses. Although mortality rates are higher in patients with sepsis with hypocalcaemia, replacement therapy is not associated with improved outcomes $^{(134)}$.

Current research investigates the effects of administration of the pharmaceutical form of $25(\mathrm{OH}) \mathrm{D}$, calcifediol and active vitamin D or analogues in critically ill patients ${ }^{(105,135,136)}$. With these forms, the consequences of impaired absorption and activation of native vitamin D may be reduced. Patients with intestinal malfunction, fat malabsorption and poor liver function may benefit more from supplementation with $25(\mathrm{OH}) \mathrm{D}$. The absorption of this form does not depend on fat absorption or the formation of chylomicrons, does not require hepatic hydroxylation and leads to a faster and proportionally higher increment in plasma $25(\mathrm{OH}) \mathrm{D}$ per unit given compared with vitamin $\mathrm{D}^{(71,137-140)}$. In addition, limited evidence in CKD stage 2-4 patients has shown that administration of the slow-release formulation of $25(\mathrm{OH}) \mathrm{D}$ is not associated with an increase in FGF23 $3^{(141,142)}$, observed with higher dosages of oral vitamin $\mathrm{D}^{(143)}$. This may be of particular importance for severely ill patients since, in many, production of renal and possibly extra-renal $1,25(\mathrm{OH})_{2} \mathrm{D}$ is impeded due to renal impairment and increased catabolism, as described in the previous section. To date, the availability of this form is, however, limited. In patients with renal impairment and AKI, administration of active vitamin D or analogues may be considered, similar to those for patients with CKD. A combination with native vitamin D to ensure tissue availability of $25(\mathrm{OH}) \mathrm{D}$ for extra-renal hydroxylation may be beneficial in this group ${ }^{(135,144)}$.

Together, the contrasting findings between observational, mechanistic and intervention studies suggest that many factors other than vitamin D status and intake play a role. The extensive alterations of vitamin D metabolism with disease processes may influence its function. With acute and severe illness, other drivers and regulatory factors of the immune and inflammatory response may be predominant and may be determined by alterations in organ function and tissue damage.

\section{Implications for practice}

\section{Prevention of vitamin D deficiency and population guidelines}

Thresholds for vitamin D deficiency for the general population differ between advisory bodies, but most define plasma $25(\mathrm{OH}) \mathrm{D}$ values below $25-30 \mathrm{nmol} / \mathrm{L}$ as deficient (reviewed in Refs. ${ }^{(23-25,145)}$ ). There is considerable variation between health authorities in the definition and thresholds or ranges of $25(\mathrm{OH}) \mathrm{D}$ concentration that encompasses vitamin D sufficiency or target ranges of $25(\mathrm{OH}) \mathrm{D}$ on which to base dietary recommendations $^{(25,145)}$. Recommended $25(\mathrm{OH}) \mathrm{D}$ target concentrations and thresholds for deficiency for specific patient groups and clinical management may be higher than for generally healthy people (reviewed in Refs. ${ }^{(25,145)}$ ).

The threshold for deficiency is the concentration of $25(\mathrm{OH}) \mathrm{D}$ below which the risk of disease increases. This is predominantly based on health outcomes related to calcium metabolism and musculoskeletal health, but in some guidelines also other health outcomes are considered. Although vitamin D deficiency is associated with many other health outcomes, discordant findings between observational studies and RCTs of vitamin D treatment are reported. An overview is beyond the scope of this manuscript and reviewed elsewhere ${ }^{(26-28)}$.

Population guidelines for dietary vitamin D intakes are partly based on the required intakes to prevent vitamin D deficiency or to achieve pre-defined target ranges of $25(\mathrm{OH}) \mathrm{D}$ or sufficiency. Also evidence from RCTs and other research designs linking vitamin D intake and status to health outcomes are considered. Dietary reference values or equivalents, defined by different public health institutes, vary as a consequence of differences 
in the defined threshold for deficiency, sufficiency or target values for $25(\mathrm{OH}) \mathrm{D}$ (reviewed in Refs. ${ }^{(25,145)}$ ). Guidelines for dietary intakes and supplementation also depend on age group, physiological state, risk factors (as per below) and, in some countries, season. An overview of population guidelines from health authorities across the world was recently published by Bouillon $^{(145)}$. In most guidelines, it is acknowledged that the majority of people do not consume sufficient vitamin D through diet alone and, thus, supplementation is needed to meet requirements. In most guidelines, a contribution of cutaneous synthesised vitamin $\mathrm{D}$ is taken into account in the formulation of recommendations of dietary requirements. Advice on sunshine exposure to maintain vitamin D status is generally not provided in view of the variability in the response to cutaneous exposure and the risk of skin damage.

In temperate climates, supplementation is recommended during winter months. Supplementation throughout the year is recommended for pregnant women and people at increased risk of deficiency. At risk are population groups with a dark skin tone, obesity and limited skin exposure to the sun (i.e. with a habitual dress style that covers most of the body, frequent sunscreen use, limited access to the outdoors, e.g. when mobility is limited or living in residential care and during illness). It seems appropriate to also apply this recommendation to those that are in prolonged self-isolation and therefore mostly indoors. Screening of vitamin $\mathrm{D}$ status is not recommended for the general population. This is limited to individuals at increased risk of deficiency (as described above) or who are symptomatic ${ }^{(15,23,145)}$.

\section{Symptoms and correction of vitamin D deficiency}

The main manifestation of severe vitamin D deficiency is osteomalacia in adults and rickets in children. It is associated with secondary hyperparathyroidism, bone loss, muscle weakness, falls and fragility fractures and, in children, also cardiomyopathy and hypocalcaemia. Clinical symptoms of vitamin D deficiency are non-specific and include generalised muscle, joint and bone pain and hyperalgesia, fatigue and muscle weakness, especially of the extremities and pelvic region, manifesting in difficulties in rising from a sitting or squatting position or a waddling gait ${ }^{(146)}$ (https://www.endocrinology.org/media/3593/nos_vitamin_d_ and_bone_-health_in_adults_web.pdf).

When vitamin $\mathrm{D}$ deficiency is present (ideally assessed on basis of plasma $25(\mathrm{OH}) \mathrm{D})$, or strongly suspected on the basis of clinical symptoms in combination with primary risk factors (see previous sections), higher intakes than daily population requirements are required. Recommendations for dosage regimens depend on local health authorities and specific patient characteristics and target ranges for $25(\mathrm{OH}) \mathrm{D}$ (see section below). In the UK, an intake of $800 \mathrm{IU} / \mathrm{d}$ is advised when vitamin $\mathrm{D}$ deficiency is mild and correction is not urgently required. This approach does not generally require clinical testing and management. When rapid correction of deficiency is needed, such as in patients with severe deficiency or with symptomatic disease, the recommended treatment regimen is based on fixed loading doses followed by maintenance therapy. Loading regimens aim to provide a total of approximately 300,000 IU given over a period of 6-10 weeks as weekly or daily split doses. Similarly, the US Endocrine Society recommends a loading dose of 300,000-400,000 IU given over 8 weeks $^{(145,147)}$. Maintenance regimens recommend intakes of $800-2000$ IU daily (up to a maximum of 4000 IU daily), given either daily or intermittently at a higher equivalent dose. Treatment with these higher dosage schedules should be monitored with appropriate clinical testing and management. Large loading dosages exceeding 60,000 IU given at once should be avoided (https://cks.nice.org.uk/ topics/vitamin-d-deficiency-in-adults-treatment-prevention and www.endocrinology.org/media/3593/nos_vitamin_d_and_ bone_-health_in_adults_web.pdf) ${ }^{(145,147)}$. High bolus dosages are associated with an increased risk of falling in adults. In addition, higher dosages, including when given as a bolus, have a different and potentially disadvantageous pharmacokinetic profile ${ }^{(71,148)}$; with a high bolus dose, the plasma concentration of $25(\mathrm{OH}) \mathrm{D}$ rapidly increases, and there may also be a small increase in $1,25(\mathrm{OH})_{2} \mathrm{D}^{(149)}$. This is followed by an increase in catabolism through increased 24-hydroxylation. This is partly mediated through an increase in FGF23 $3^{(133,143,150)}$ and $1,25(\mathrm{OH})_{2} \mathrm{D}$ itself ${ }^{(149,151)}$. This results in increased conversion into $24,25(\mathrm{OH})_{2} \mathrm{D}$ and potentially other catabolic products from $25(\mathrm{OH}) \mathrm{D}$ and possibly vitamin $\mathrm{D}$ itself. Also, the rate of catabolism of $1,25(\mathrm{OH})_{2} \mathrm{D}$ is expected to increase ${ }^{(133,149,151)}$.

\section{Guidelines for prevention and correction of vitamin $D$ deficiency in specific patient groups}

Recommended intakes, 25(OH)D target concentrations and thresholds for deficiency for specific patient groups and clinical management may be higher than for generally healthy people $^{(145)}$. They consider altered supply or bio-availability, losses, increased metabolism and/or requirements or a combination of these factors. Little is known about the vitamin D requirements during acute or chronic illness. Even for chronic conditions that clearly affect vitamin D metabolism (such as renal ${ }^{(144)}$ and hepatic disease ${ }^{(152-154)}$ ) or bioavailability (conditions affecting intestinal fat and/or vitamin D absorption such as with coeliac and inflammatory bowel disease ${ }^{(155,156)}$ ), direct evidence on requirements is scarce. Also certain types of medication are associated with altered vitamin D metabolism, such as corticosteroids, anti-epileptic drugs and drugs inhibiting fat

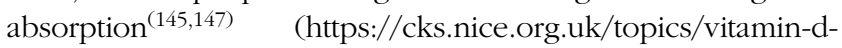
deficiency-in-adults-treatment-prevention), or increased dietary calcium requirements, such as medications reducing bone loss. With these conditions, specific patient management guidelines should be followed, where formulated ( renal $^{(144,25)}$; hepatic $^{(152-154)}$; coeliac $^{(155)}$; inflammatory bowel disease ${ }^{(156)}$; osteoporosis (theros.org.uk)). Many guidelines recommend regular testing of vitamin $\mathrm{D}$ status and correction of deficiency if and as required with monitoring of side effects and until a target plasma concentration or range of $25(\mathrm{OH}) \mathrm{D}$ is reached. Dependent on the aspect of metabolism affected and severity or disease, guidelines may recommend prescribing native vitamin $\mathrm{D}, 25(\mathrm{OH}) \mathrm{D}$ or active vitamin $\mathrm{D}$ or their analogues $^{(144,152-154,157-159)}$. 


\section{Management of vitamin D status in people with acute and critical illness}

Little is known about the vitamin D requirements during acute and critical illness or with inflammation ${ }^{(23,136)}$.

For patients with mild and short-term acute illnesses, such as during a mild disease course following infection with SARS-CoV2 and/or during self-isolation, supplementation with vitamin $D$ to prevent vitamin D deficiency according to population guidelines for groups with no or limited sun exposure is appropriate ${ }^{(23,145)}$. In the presence of risk factors or symptoms of deficiency, testing of vitamin D status and correction of vitamin D deficiency is warranted, as described above.

There is no specific guidance to prevent vitamin D deficiency in severely ill patients ${ }^{(136)}$. The standard formulations for enteral feeding contain 200-400 IU vitamin D per day, and parenteral multivitamin preparations typically contain only 200 or 220 IU per day. This is below the population recommendations in the majority of countries. As outlined in previous sections, patients with acute and critical illness are often vitamin D deficient at admission and may have a rapid decline in vitamin D status, suggesting that vitamin $\mathrm{D}$ requirements are increased. This may be the result of altered bioavailability or metabolism, increased utilisation and losses of $1,25(\mathrm{OH})_{2} \mathrm{D}$ and $25(\mathrm{OH}) \mathrm{D}$ and medication use increasing catabolism, such as corticosteroids. The most recent update for critically ill patients recommends screening of patients for vitamin D deficiency and those with plasma $25(\mathrm{OH}) \mathrm{D}$ concentrations below $30 \mathrm{nmol} / \mathrm{L}$ to be supplemented with a single high dose of vitamin $\mathrm{D}_{3}(500,000 \mathrm{IU})$ within a week after admission ${ }^{(160,161)}$. No guidance is available regarding monitoring, frequency of testing and maintenance therapy. Considering the likelihood of increased requirements, it seems reasonable to provide regular (daily or weekly) vitamin D supplementation similar to the maintenance schedules recommended for patients after correction of vitamin D deficiency, as described above with regular testing of plasma 25(OH)D.

In consideration of underlying conditions and acute alterations in organ function with critical illness, the use of activated or partly activated vitamin D metabolites may be considered. Current research investigates the effects of administration of $25(\mathrm{OH}) \mathrm{D}$ and active vitamin $\mathrm{D}$ in critically ill patients, but this research is as yet not incorporated in guidelines.

\section{Conclusions}

No data are yet available demonstrating a causative link between low vitamin D status and susceptibility for COVID-19 or its disease course. Data from observation studies investigating the association between vitamin D status and risk of infection and/or developing severe symptoms are conflicting. Vitamin $\mathrm{D}$ deficiency is highly prevalent in patients hospitalised with COVID-19 and with other conditions, particularly those that are severely ill. This may be related to the presence of risk factors for vitamin D deficiency, associated with their general poor health status or increased catabolism and losses of 25(OH)D during disease. There are extensive alterations in vitamin D metabolism with severe illness and inflammatory processes which may increase requirements of vitamin $\mathrm{D}$. This needs consideration in the assessment of associations with disease risk and severity and in patient management. Although mechanistic studies show that vitamin D metabolites and DBP have multi-factorial roles in pulmonary health, immune function and inflammatory response to viral infection and tissue damage, supplementation of ICU patients has so far, however, shown little effect. The contrasting findings between observational, mechanistic and intervention studies suggest that many other factors play a role. Alterations in vitamin D metabolism with disease processes may influence its function, and/or other drivers of the immune and inflammatory response may be predominant. The effect may depend on when supplementation is initiated relative to the development of disease symptoms and progression to severe illness and the frequency of administration. Such data are not yet available. The beneficial effects of vitamin D may also be limited to specific subgroups.

There is some evidence that vitamin D supplementation decreases the risk of respiratory tract infections, particularly in children, although the risk reduction is moderate. No such evidence is yet available for the prevention or treatment of COVID19. In view of the high prevalence of vitamin D deficiency, proactively applying current population and patient management guidelines to prevent and correct vitamin D deficiency with screening and monitoring of vitamin $\mathrm{D}$ status in individuals who are at increased risk is appropriate.

\section{Acknowledgements}

This work was supported by The Academy of Medical Sciences [SBF002 $\backslash 1097]$ and the University of East Anglia Health and Social Care Partners, UK.

\section{Author contributions}

I.S.: conceptualisation; I.S., W.D.F. and A.F.: all authors have contributed to the interpretation, drafting and approval of the final version of this manuscript.

The authors declare no conflicts of interest.

\section{References}

1. Velavan TP \& Meyer CG (2020) Mild versus severe COVID-19: laboratory markers. Int J Infect Dis 95, 304-307.

2. Docherty AB, Harrison EM, Green CA, et al. (2020) Features of 20133 UK patients in hospital with covid-19 using the ISARIC WHO Clinical Characterisation Protocol: prospective observational cohort study. BMJ 369, m1985.

3. Williamson EJ, Walker AJ, Bhaskaran K, et al. (2020) Factors associated with COVID-19-related death using OpenSAFELY. Nature 584, 430-436.

4. Huang C, Soleimani J, Herasevich S, et al. (2021) Clinical characteristics, treatment, and outcomes of critically ill patients with COVID-19: a scoping review. Mayo Clin Proc 96, 183-202.

5. Triggle CR, Bansal D, Ding H, et al. (2021) A comprehensive review of viral characteristics, transmission, pathophysiology, immune response, and management of SARS-CoV-2 and COVID-19 as a basis for controlling the pandemic. Front Immunol 12, 631139 
6. Santaolalla A, Beckmann K, Kibaru J, Josephs D, Van Hemelrijck M \& Irshad S (2020) Association between vitamin D and novel SARS-CoV-2 respiratory dysfunction - a scoping review of current evidence and its implication for COVID-19 pandemic. Front Physiol 11, 564387.

7. Group RC, Horby P, Lim WS, et al. (2021) Dexamethasone in hospitalized patients with Covid-19. N Engl J Med 384, 693-704.

8. Bloch EM, Shoham S, Casadevall A, et al. (2020) Deployment of convalescent plasma for the prevention and treatment of COVID-19. J Clin Invest 130, 2757-2765.

9. Casadevall A, Joyner MJ \& Pirofski LA (2020) A randomized trial of convalescent plasma for COVID-19-potentially hopeful signals. JAMA 324, 455-457.

10. Quesada-Gomez JM, Entrenas-Castillo M \& Bouillon R (2020) Vitamin D receptor stimulation to reduce acute respiratory distress syndrome (ARDS) in patients with coronavirus SARSCoV-2 infections: revised Ms SBMB 2020_166. J Steroid Biochem Mol Biol 202, 105719.

11. Martineau AR, Jolliffe DA, Hooper RL, et al. (2017) Vitamin D supplementation to prevent acute respiratory tract infections: systematic review and meta-analysis of individual participant data. BMJ 356, i6583.

12. Greiller CL \& Martineau AR (2015) Modulation of the immune response to respiratory viruses by vitamin D. Nutrients $\mathbf{7}$, $4240-4270$

13. Ginde AA, Blatchford P, Breese K, et al. (2017) High-dose monthly vitamin $\mathrm{D}$ for prevention of acute respiratory infection in older long-term care residents: a randomized clinical trial. J Am Geriatr Soc 65, 496-503.

14. Vuichard Gysin D, Dao D, Gysin CM, Lytvyn L \& Loeb M (2016) Effect of vitamin D3 supplementation on respiratory tract infections in healthy individuals: a systematic review and meta-analysis of randomized controlled trials. PLoS One 11, e0162996.

15. Vitamin D and acute respiratory tract infections (2020) (https://www.gov.uk/government/groups/scientific-advisorycommittee-on-nutrition). In: Nutrition SACo, editor.

16. Ney J, Heyland DK, Amrein K, et al. (2019) The relevance of 25-hydroxyvitamin D and 1,25-dihydroxyvitamin D concentration for postoperative infections and postoperative organ dysfunctions in cardiac surgery patients: The eVIDenCe study. Clin Nutr 38, 2756-2762.

17. Kempker JA, Tangpricha V, Ziegler TR \& Martin GS (2012) Vitamin D in sepsis: from basic science to clinical impact. Crit Care 16, 316

18. Entrenas Castillo M, Entrenas Costa LM, Vaquero Barrios JM, et al. (2020) Effect of calcifediol treatment and best available therapy versus best available therapy on intensive care unit admission and mortality among patients hospitalized for COVID-19: a pilot randomized clinical study. I Steroid Biochem Mol Biol 203, 105751.

19. Murai IH, Fernandes AL, Sales LP, et al. (2021) Effect of a single high dose of vitamin D3 on hospital length of stay in patients with moderate to severe COVID-19: a randomized clinical trial. JAMA 325, 1053-1060.

20. Nogues X, Ovejero D, Pineda-Moncusi M, et al. (2021) Calcifediol treatment and COVID-19-related outcomes. $J$ Clin Endocrinol Metab. Online ahead of print. doi: 10.1210/ clinem/dgab405

21. Chakhtoura M, Napoli N \& El Hajj Fuleihan G (2020) Commentary: myths and facts on vitamin D amidst the COVID-19 pandemic. Metabolism 109, 154276.

22. Raisi-Estabragh Z, Martineau AR, Curtis EM, et al. (2021) Vitamin D and coronavirus disease 2019 (COVID-19): rapid evidence review. Aging Clin Exp Res 33, 2031-2041.
23. SACN Vitamin D and Health Report (2016) In: Nutrition TSACo, editor. London: The Stationery Office (https://www. gov.uk/government/publications/sacn-vitamin-d-and-healthreport).

24. Institute of Medicine of the National Academies (2011) Dietary reference intakes for calcium and vitamin $D, 1$ ed. Washington, DC, The National Academies Press.

25. Christodoulou M, Aspray TJ \& Schoenmakers I (2021) Vitamin D supplementation for patients with chronic kidney disease: a systematic review and meta-analyses of trials investigating the response to supplementation and an overview of guidelines. Calcif Tissue Int 109, 157-178.

26. Rejnmark L, Bislev LS, Cashman KD, et al. (2017) Non-skeletal health effects of vitamin D supplementation: a systematic review on findings from meta-analyses summarizing trial data. PLoS One 12, e0180512.

27. Maretzke F, Bechthold A, Egert S, et al. (2020) Role of vitamin $\mathrm{D}$ in preventing and treating selected extraskeletal diseases-an umbrella review. Nutrients $\mathbf{1 2}, 969$.

28. Akutsu T, Kitamura H, Himeiwa S, Kitada S, Akasu T \& Urashima M (2020) Vitamin D and cancer survival: does vitamin D supplementation improve the survival of patients with cancer? Curr Oncol Rep 22, 62.

29. Dawson-Hughes B, Staten MA, Knowler WC, et al. (2020) Intratrial exposure to vitamin $\mathrm{D}$ and new-onset diabetes among adults with prediabetes: a secondary analysis from the vitamin D and type 2 diabetes (D2d) study. Diabetes Care 43, 2916-2922.

30. Macdonald HM, Reid IR, Gamble GD, Fraser WD, Tang JC \& Wood AD (2018) 25-Hydroxyvitamin D threshold for the effects of vitamin D supplements on bone density: secondary analysis of a randomized controlled trial.J Bone Miner Res $\mathbf{3 3}$, 1464-1469.

31. Bischoff-Ferrari HA (2008) Optimal serum 25-hydroxyvitamin $\mathrm{D}$ levels for multiple health outcomes. Adv Exp Med Biol 624, 55-71.

32. Chandler PD, Chen WY, Ajala ON, et al. (2020) Effect of vitamin D3 supplements on development of advanced cancer: a secondary analysis of the VITAL randomized clinical trial. JAMA Network Open 3, e2025850.

33. Bilezikian JP, Bikle D, Hewison M, et al. (2020) Mechanisms in endocrinology: vitamin D and COVID-19. Eur J Endocrinol 183, R133-R147.

34. D'Avolio A, Avataneo V, Manca A, et al. (2020) 25Hydroxyvitamin D concentrations are lower in patients with positive PCR for SARS-CoV-2. Nutrients 12, 1359.

35. Sun JK, Zhang WH, Zou L, et al. (2020) Serum calcium as a biomarker of clinical severity and prognosis in patients with coronavirus disease 2019. Aging 12, 11287-11295.

36. Pereira M, Dantas Damascena A, Galvão Azevedo LM, de Almeida Oliveira T \& da Mota Santana J (2020) Vitamin D deficiency aggravates COVID-19: systematic review and metaanalysis. Crit Rev Food Sci Nutr 1-9.

37. Ye K, Tang F, Liao X, et al. (2020) Does serum vitamin D level affect COVID-19 infection and its severity?-a case-control study. J Am Coll Nutr 1-8.

38. Panagiotou G, Tee SA, Ihsan Y, et al. (2020) Original publication: low serum 25-hydroxyvitamin D (25[OH]D) levels in patients hospitalized with COVID-19 are associated with greater disease severity. Clin Endocrinol (Oxf) 93 , 629-630.

39. Meltzer DO, Best TJ, Zhang H, Vokes T, Arora VM \& Solway J (2021) Association of vitamin D levels, race/ethnicity, and clinical characteristics with COVID-19 test results. JAMA Network Open 4, e214117. 
40. Radujkovic A, Hippchen T, Tiwari-Heckler S, Dreher S, Boxberger M \& Merle U (2020) Vitamin D deficiency and outcome of COVID-19 patients. Nutrients 12, 2757.

41. Pizzini A, Aichner M, Sahanic S, et al. (2020) Impact of vitamin D deficiency on COVID-19-A prospective analysis from the CovILD registry. Nutrients $\mathbf{1 2}, 2775$.

42. Harrison EM (2020) Ethnicity and outcomes from COVID-19: the ISARIC CCP-UK prospective observational cohort study of hospitalised patients. Lancet Pre-print (https:// papersssrncom $/$ sol3/paperscfm?abstract_id=3618215).

43. Pan D, Sze S, Minhas JS, et al. (2020) The impact of ethnicity on clinical outcomes in COVID-19: a systematic review. EClinicalMedicine 23, 100404.

44. Raisi-Estabragh Z, McCracken C, Bethell MS, et al. (2020) Greater risk of severe COVID-19 in Black, Asian and Minority Ethnic populations is not explained by cardiometabolic, socioeconomic or behavioural factors, or by $25(\mathrm{OH})$ vitamin D status: study of 1326 cases from the UK Biobank. J Public Health 42, 451-460.

45. Chastain DB, Osae SP, Henao-Martínez AF, Franco-Paredes C, Chastain JS \& Young HN (2020) Racial disproportionality in Covid clinical trials. $N$ Engl J Med 383, e59.

46. Kaufman HW, Niles JK, Kroll MH, Bi C \& Holick MF (2020) SARS-CoV-2 positivity rates associated with circulating 25hydroxyvitamin D levels. PLoS One 15, e0239252.

47. Chaturvedi N (2003) Ethnic differences in cardiovascular disease. Heart 89, 681-686.

48. Reitsma MB, Claypool AL, Vargo J, et al. (2021) Racial/ethnic disparities in COVID-19 exposure risk, testing, and cases at the subcounty level in California. Health Affairs 40, 870-878.

49. Hastie CE, Mackay DF, Ho F, et al. (2020) Vitamin D concentrations and COVID-19 infection in UK Biobank. Diabetes Metab Syndr 14, 561-565.

50. Hastie CE, Pell JP \& Sattar N. (2021) Vitamin D and COVID-19 infection and mortality in UK Biobank. Eur J Nutr 60, 545-548.

51. Meltzer DO, Best TJ, Zhang H, Vokes T, Arora V \& Solway J (2020) Association of vitamin D status and other clinical characteristics with COVID-19 test results. JAMA Network Open 3, e2019722.

52. Merzon E, Tworowski D, Gorohovski A, et al. (2020) Low plasma $25(\mathrm{OH})$ vitamin D level is associated with increased risk of COVID-19 infection: an Israeli population-based study. FEBS J 287, 3693-3702.

53. Schoenmakers I, Gousias P, Jones KS \& Prentice A (2016) Prediction of winter vitamin $\mathrm{D}$ status and requirements in the UK population based on $25(\mathrm{OH})$ vitamin D half-life and dietary intake data.J Steroid Biochem Mol Biol 164, 218-222.

54. Li Y, Wang X \& Nair H (2020) Global seasonality of human seasonal coronaviruses: a clue for postpandemic circulating season of severe acute respiratory syndrome coronavirus 2 ? J Infect Dis 222, 1090-1097.

55. Ianevski A, Zusinaite E, Shtaida N, et al. (2019) Low temperature and low UV indexes correlated with peaks of influenza virus activity in Northern Europe during 2010(-) 2018. Viruses 11, 207.

56. Rhodes JM, Subramanian S, Laird E, Griffin G \& Kenny RA (2021) Perspective: vitamin D deficiency and COVID-19 severity - plausibly linked by latitude, ethnicity, impacts on cytokines, ACE2 and thrombosis. J Intern Med 289, 97-115.

57. Rhodes JM, Subramanian S, Laird E \& Kenny RA (2020) Editorial: low population mortality from COVID-19 in countries south of latitude 35 degrees North supports vitamin D as a factor determining severity. Aliment Pharmacol Ther 51, 1434-1437.

58. Rastogi A, Bhansali A, Khare N, et al. (2020) Short term, highdose vitamin D supplementation for COVID-19 disease: a randomised, placebo-controlled, study (SHADE study). Postgrad Med J. doi: 10.1136/ postgradmedj-2020-139065

59. Annweiler C, Hanotte B, Grandin de l'Eprevier C, Sabatier JM, Lafaie L \& Celarier T (2020) Vitamin D and survival in COVID19 patients: a quasi-experimental study.J Jteroid Biochem Mol Biol 204, 105771.

60. Annweiler G, Corvaisier M, Gautier J, et al. (2020) Vitamin D supplementation associated to better survival in hospitalized frail elderly COVID-19 patients: the GERIA-COVID Quasiexperimental study. Nutrients 12, 3377.

61. Jolliffe DA, Camargo CA, Jr., Sluyter JD, et al. (2021) Vitamin D supplementation to prevent acute respiratory infections: a systematic review and meta-analysis of aggregate data from randomised controlled trials. Lancet Diabetes Endocrinol 9 , 276-292.

62. Martineau AR, Jolliffe DA, Greenberg L, et al. (2019) Vitamin D supplementation to prevent acute respiratory infections: individual participant data meta-analysis. Health Technol Assess 23, $1-44$.

63. Vo P, Koppel C, Espinola JA, et al. (2018) Vitamin D status at the time of hospitalization for bronchiolitis and its association with disease severity. J Pediatr 203, 416-22.e1.

64. Hewison M (2012) Vitamin D and immune function: an overview. Proc Nutr Soc 71, 50-61.

65. Bilezikian JP, Bikle D, Hewison M, et al. (2020) Mechanisms in endocrinology: vitamin D and COVID-19. Eur J Endocrinol 183, R133-R147.

66. Kumar R, Rathi H, Haq A, Wimalawansa SJ \& Sharma A (2021) Putative roles of vitamin $\mathrm{D}$ in modulating immune response and immunopathology associated with COVID-19. Virus Res 292, 198235.

67. Zheng G, Pan M, Li Z, Xiang W \& Jin W (2018) Effects of vitamin D on apoptosis of T-lymphocyte subsets in neonatal sepsis. Exp Ther Med 16, 629-634.

68. de Carvalho JTG, Schneider M, Cuppari L, Grabulosa CC, Cendoroglo M \& Dalboni MA (2019) Cholecalciferol supplementation did not change interleukin-7 and B cell-activating factor levels and CD95 expression in B lymphocytes in patients on dialysis: a randomized pilot-controlled trial. $J$ Ren Nutr 29, 454-461.

69. Sette A \& Crotty S (2021) Adaptive immunity to SARS-CoV-2 and COVID-19. Cell 184, 861-880.

70. Garvin MR, Alvarez C, Miller JI, et al. (2020) A mechanistic model and therapeutic interventions for COVID-19 involving a RAS-mediated bradykinin storm. Elife 9 , e59177.

71. Schoenmakers I \& Jones KS (2017) Pharmacology and pharmacokinetics of vitamin D. In Feldman D, Pike W, Goltzman D, Giovannucc iE, Hewison M, Bouillon R, editors. Vitamin $D$. 5th ed, Chapter 37. San Diego: ELSEVIER; pp. 635-661.

72. Kew RR (2019) The vitamin D binding protein and inflammatory injury: a mediator or sentinel of tissue damage? Front Endocrinol (Lausanne) 10, 470.

73. Zittermann A, Ernst JB, Birschmann I \& Dittrich M (2015) Effect of vitamin D or activated vitamin D on circulating 1,25-dihydroxyvitamin D concentrations: a systematic review and metaanalysis of randomized controlled trials. Clin Chem 61, 1484-1494.

74. Schwartz JB, Gallagher JC, Jorde R, et al. (2018) Determination of free $25(\mathrm{OH}) \mathrm{D}$ concentrations and their relationships to total 25(OH)D in multiple clinical populations. J Clin Endocrinol Metab 103, 3278-3288.

75. Chun RF, Peercy BE, Orwoll ES, Nielson CM, Adams JS \& Hewison M (2014) Vitamin D and DBP: the free hormone hypothesis revisited. J Steroid Biochem Mol Biol 144, 132-137. 
76. Bouillon R, Schuit F, Antonio L \& Rastinejad F (2019) Vitamin D binding protein: a historic overview. Front Endocrinol (Lausanne) 10, 910

77. Chishimba L, Thickett DR, Stockley RA \& Wood AM (2010) The vitamin D axis in the lung: a key role for vitamin D-binding protein. Thorax 65, 456-462.

78. Hiemstra TF, Casian A, Boraks P, Jayne DR \& Schoenmakers I (2014) Plasma exchange induces vitamin D deficiency. QJM 107, 123-130.

79. Nielson CM, Jones KS, Bouillon R, et al. (2016) Role of assay type in determining free 25-hydroxyvitamin $\mathrm{D}$ levels in diverse populations. N Engl J Med 374, 1695-1696.

80. Gomme PT \& Bertolini J (2004) Therapeutic potential of vitamin D-binding protein. Trends Biotechnol 22, 340-345.

81. Guha C, Osawa M, Werner PA, Galbraith RM \& Paddock GV (1995) Regulation of human Gc (vitamin D-binding) protein levels: hormonal and cytokine control of gene expression in vitro. Hepatology 21, 1675-1681.

82. Dahl B, Schiødt FV, Rudolph S, Ott P, Kiaer T \& Heslet L (2001) Trauma stimulates the synthesis of Gc-globulin. Intensive Care Med 27, 394-399.

83. Speeckaert MM, Speeckaert R, van Geel N \& Delanghe JR (2014) Vitamin D binding protein: a multifunctional protein of clinical importance. Adv Clin Chem 63, 1-57.

84. Leaf DE, Waikar SS, Wolf M, Cremers S, Bhan I \& Stern L (2013) Dysregulated mineral metabolism in patients with acute kidney injury and risk of adverse outcomes. Clin Endocrinol (Oxf) 79, 491-498.

85. Silva MC \& Furlanetto TW (2015) Does serum 25-hydroxyvitamin D decrease during acute-phase response? A systematic review. Nutr Res 35, 91-96.

86. Kim HJ, Ji M, Song J, Moon HW, Hur M \& Yun YM (2017) Clinical utility of measurement of vitamin D-binding protein and calculation of bioavailable vitamin $\mathrm{D}$ in assessment of vitamin D status. Ann Lab Med 37, 34-38.

87. Waldron JL, Ashby HL, Cornes MP, et al. (2013) Vitamin D: a negative acute phase reactant. J Clin Pathol 66, 620-622.

88. Meier U, Gressner O, Lammert F \& Gressner AM (2006) Gc-globulin: roles in response to injury. Clin Chem $\mathbf{5 2}$ 1247-1253.

89. Hewison $\mathrm{M}$ (2012) Vitamin D and immune function: autocrine, paracrine or endocrine? Scand J Clin Lab Invest Suppl $\mathbf{2 4 3}$ 92-102.

90. Pihl TH, Jørgensen CS, Santoni-Rugiu E, et al. (2010) Safety pharmacology, toxicology and pharmacokinetic assessment of human Gc globulin (vitamin D binding protein). Basic Clin Pharmacol Toxicol 107, 853-860.

91. Ge L, Trujillo G, Miller EJ \& Kew RR (2014) Circulating complexes of the vitamin D binding protein with G-actin induce lung inflammation by targeting endothelial cells. Immunobiology 219, 198-207.

92. Amrein K, Oudemans-van Straaten HM \& Berger MM (2018) Vitamin therapy in critically ill patients: focus on thiamine, vitamin C, and vitamin D. Intensive Care Med 44, 1940-1944.

93. Cariolou M, Cupp MA, Evangelou E, Tzoulaki I \& BerlangaTaylor AJ (2019) Importance of vitamin D in acute and critically ill children with subgroup analyses of sepsis and respiratory tract infections: a systematic review and metaanalysis. BMJ Open 9, e027666.

94. McNally JD, Nama N, O'Hearn K, et al. (2017) Vitamin D deficiency in critically ill children: a systematic review and metaanalysis. Crit Care 21, 287.

95. Quraishi SA, Bittner EA, Blum L, McCarthy CM, Bhan I \& Camargo CA Jr. (2014) Prospective study of vitamin D status at initiation of care in critically ill surgical patients and risk of 90-day mortality. Crit Care Med 42, 1365-1371.
96. Quraishi SA \& Camargo CA Jr (2012) Vitamin D and major chronic illness. J Restor Med 1, 9-23.

97. Zajic P, Heschl S, Schorghuber M, et al. (2021) Vitamin D assessment in perioperative medicine and critical care: a prospective observational pilot study. Wien Klin Wochenschr 133, 79-85.

98. Martucci G, Tuzzolino F, Arcadipane A, et al. (2017) The effect of high-dose cholecalciferol on bioavailable vitamin D levels in critically ill patients: a post hoc analysis of the VITdAL-ICU trial. Intensive Care Med 43, 1732-1734.

99. Martucci G, McNally D, Parekh D, et al. (2019) Trying to identify who may benefit most from future vitamin $\mathrm{D}$ intervention trials: a post hoc analysis from the VITDAL-ICU study excluding the early deaths. Crit Care 23, 200.

100. Smolders J, van den Ouweland J, Geven C, Pickkers P \& Kox M (2021) Letter to the editor: vitamin D deficiency in COVID-19: mixing up cause and consequence. Metabolism 115, 154434.

101. Lohia P, Kapur S, Patel P \& Seyoum B (2021) Letter to the editor: vitamin D levels in acute illness and clinical severity in COVID-19 patients. Respir Res 22, 102.

102. Li CH, Tang X, Wasnik S, et al. (2019) Mechanistic study of the cause of decreased blood 1,25-dihydroxyvitamin D in sepsis. BMC Infect Dis 19, 1020.

103. Mata-Granados JM, Vargas-Vasserot J, Ferreiro-Vera C, Luque de Castro MD, Pavon RG \& Quesada Gomez JM (2010) Evaluation of vitamin D endocrine system (VDES) status and response to treatment of patients in intensive care units (ICUs) using an on-line SPE-LC-MS/MS method. J Steroid Biochem Mol Biol 121, 452-455.

104. Amrein K, Schnedl C, Holl A, et al. (2014) Effect of high-dose vitamin D3 on hospital length of stay in critically ill patients with vitamin D deficiency: the VITdAL-ICU randomized clinical trial. JAMA 312, 1520-1530.

105. Ingels C, Vanhorebeek I, Van Cromphaut S, et al. (2020) Effect of Intravenous 25OHD supplementation on bone turnover and inflammation in prolonged critically ill patients. Horm Metab Res 52, 168-178.

106. Chand S, Kapoor S, Orsi D, et al. (2020) COVID-19-associated critical illness-report of the first 300 patients admitted to intensive care units at a New York city medical center. I Intensive Care Med 35, 963-970.

107. Robbins-Juarez SY, Qian L, King KL, et al. (2020) Outcomes for patients with COVID-19 and acute kidney injury: a systematic review and meta-analysis. Kidney Int Rep 5, 1149-1160.

108. Briggs AD, Kuan V, Greiller CL, et al. (2013) Longitudinal study of vitamin D metabolites after long bone fracture. $J$ Bone Miner Res 28, 1301-1307.

109. Reid D, Toole BJ, Knox S, et al. (2011) The relation between acute changes in the systemic inflammatory response and plasma 25-hydroxyvitamin D concentrations after elective knee arthroplasty. Am J Clin Nutr 93, 1006-1011.

110. Suberviola B, Lavin BA, Jimenez AF, Perez-San Martin S, Garcia-Unzueta M \& Santibañez M (2019) Vitamin D binding protein, but not vitamin D or vitamin D-related peptides, is associated with septic shock mortality. Enferm Infecc Microbiol Clin (Engl Ed) 37, 239-243.

111. Horváth-Szalai Z, Kustán P, Szirmay B, et al. (2018) Predictive value of serum gelsolin and Gc globulin in sepsis - a pilot study. Clin Chem Lab Med 56, 1373-1382.

112. Dahl B, Schiødt FV, Ott P, et al. (2003) Plasma concentration of Gc-globulin is associated with organ dysfunction and sepsis after injury. Crit Care Med 31, 152-156.

113. Goldschmidt-Clermont PJ, Lee WM \& Galbraith RM (1988) Proportion of circulating Gc (vitamin D-binding protein) in complexed form: relation to clinical outcome in fulminant hepatic necrosis. Gastroenterology 94, 1454-1458. 
114. Yoo JW, Jung YK, Ju S, et al. (2020) Serum vitamin D binding protein level, but not serum total, bioavailable, free vitamin $D$, is higher in 30-days survivors than in nonsurvivors with sepsis. Medicine (Baltimore) 99, e20756.

115. Jones KS, Redmond J, Fulford AJ, et al. (2017) Diurnal rhythms of vitamin $\mathrm{D}$ binding protein and total and free vitamin $\mathrm{D}$ metabolites. J Steroid Biochem Mol Biol 172, 130-135.

116. Hassan-Smith Z \& Cooper MS (2011) Overview of the endocrine response to critical illness: how to measure it and when to treat. Best Pract Res Clin Endocrinol Metab 25, 705-717.

117. Venkatesh B, Davidson B, Robinson K, Pascoe R, Appleton C \& Jones M (2012) Do random estimations of vitamin D3 and parathyroid hormone reflect the 24 -h profile in the critically ill? Intensive Care Med 38, 177-179.

118. Quraishi SA \& Camargo CA Jr (2012) Vitamin D in acute stress and critical illness. Curr Opin Clin Nutr Metab Care 15, 625-634

119. Amrein K, Sourij H, Wagner G, et al. (2011) Short-term effects of high-dose oral vitamin D3 in critically ill vitamin D deficient patients: a randomized, double-blind, placebo-controlled pilot study. Crit Care 15, R104.

120. Quraishi SA, De Pascale G, Needleman JS, et al. (2015) Effect of cholecalciferol supplementation on vitamin D status and cathelicidin levels in sepsis: a randomized, placebo-controlled trial. Crit Care Med 43, 1928-1937.

121. Han JE, Jones JL, Tangpricha V, et al. (2016) High dose vitamin $\mathrm{D}$ administration in ventilated intensive care unit patients: a pilot double blind randomized controlled trial. J Clin Transl Endocrinol 4, 59-65.

122. Miroliaee AE, Salamzadeh J, Shokouhi S, et al. (2017) Effect of vitamin D supplementation on procalcitonin as prognostic biomarker in patients with ventilator associated pneumonia complicated with vitamin D deficiency. Iran J Pharm Res 16, 1254-1263.

123. Ginde AA \& Talmor D (2020) High-dose vitamin D3 for critically ill vitamin D-deficient patients. Reply. NEnglJ Med 382, 1670-1671.

124. Hasanloei MAV, Rahimlou M, Eivazloo A, Sane S, Ayremlou P \& Hashemi R (2020) Effect of oral versus intramuscular vitamin $D$ replacement on oxidative stress and outcomes in traumatic mechanical ventilated patients admitted to intensive care unit. Nutr Clin Pract 35, 548-558.

125. Miri M, Kouchek M, Rahat Dahmardeh A \& Sistanizad M (2019) Effect of high-dose vitamin D on duration of mechanical ventilation in ICU patients. Iran J Pharm Res 18, 1067-1072.

126. Leaf DE, Raed A, Donnino MW, Ginde AA \& Waikar SS (2014) Randomized controlled trial of calcitriol in severe sepsis. Am J Respir Crit Care Med 190, 533-541.

127. Putzu A, Belletti A, Cassina T, et al. (2017) Vitamin D and outcomes in adult critically ill patients. A systematic review and meta-analysis of randomized trials. J Crit Care 38, 109-114.

128. Lan SH, Lai CC, Chang SP, Lu LC, Hung SH \& Lin WT (2020) Vitamin D supplementation and the outcomes of critically ill adult patients: a systematic review and meta-analysis of randomized controlled trials. Sci Rep 10, 14261.

129. Weng H, Li JG, Mao Z \& Zeng XT (2017) Randomised trials of vitamin $\mathrm{D}(3)$ for critically ill patients in adults: systematic review and meta-analysis with trial sequential analysis. Intensive Care Med 43, 277-278.

130. Langlois PL, Szwec C, D'Aragon F, Heyland DK \& Manzanares W (2018) Vitamin D supplementation in the critically ill: a systematic review and meta-analysis. Clin Nutr 37, 1238-1246.

131. Han JE, Alvarez JA, Jones JL, et al. (2017) Impact of high-dose vitamin $\mathrm{D}(3)$ on plasma free 25 -hydroxyvitamin D concentrations and antimicrobial peptides in critically ill mechanically ventilated adults. Nutrition 38, 102-108.
132. Sanders KM, Stuart AL, Williamson EJ, et al. (2010) Annual high-dose oral vitamin D and falls and fractures in older women: a randomized controlled trial. JAMA $\mathbf{3 0 3}$, $1815-1822$.

133. Griffin G, Hewison M, Hopkin J, et al. (2021) Perspective: vitamin D supplementation prevents rickets and acute respiratory infections when given as daily maintenance but not as intermittent bolus: implications for COVID-19. Clin Med (Lond) 21, e144-e149.

134. Jacobi J (2019) Management of endocrine emergencies in the ICU. J Pharm Pract 32, 314-326.

135. Leaf DE \& Christov M (2019) Dysregulated mineral metabolism in AKI. Semin Nephrol 39, 41-56.

136. Amrein K, Papinutti A, Mathew E, Vila G \& Parekh D (2018) Vitamin D and critical illness: what endocrinology can learn from intensive care and vice versa. Endocr Connect 7, R304-R315.

137. Vaes AMM, Tieland M, de Regt MF, Wittwer J, van Loon LJC \& de Groot L (2018) Dose-response effects of supplementation with calcifediol on serum 25-hydroxyvitamin D status and its metabolites: a randomized controlled trial in older adults. Clin Nutr 37, 808-814.

138. Jetter A, Egli A, Dawson-Hughes B, et al. (2014) Pharmacokinetics of oral vitamin $\mathrm{D}(3)$ and calcifediol. Bone 59, 14-19.

139. Quesada-Gomez JM \& Bouillon R (2018) Is calcifediol better than cholecalciferol for vitamin D supplementation? Osteoporos Int 29, 1697-1711.

140. Perez-Castrillon JL, Duenas-Laita A, Brandi ML, et al. (2021) Calcifediol is superior to cholecalciferol in improving vitamin D status in postmenopausal women: a randomized trial. J Bone Miner Res. Online ahead of print. doi: 10.1002/ jbmr.4387

141. Sprague SM, Silva AL, Al-Saghir F, et al. (2014) Modifiedrelease calcifediol effectively controls secondary hyperparathyroidism associated with vitamin D insufficiency in chronic kidney disease. Am J Nephrol 40, 535-545.

142. Sprague SM, Crawford PW, Melnick JZ, et al. (2016) Use of extended-release calcifediol to treat secondary hyperparathyroidism in stages 3 and 4 chronic kidney disease. $A m J$ Nephrol 44, 316-325.

143. Zittermann A, Berthold HK \& Pilz S (2021) The effect of vitamin D on fibroblast growth factor 23: a systematic review and meta-analysis of randomized controlled trials. Eur J Clin Nutr 75, 980-987.

144. KDIGO (2017) 2017 clinical practice guideline update for the diagnosis, evaluation, prevention, and treatment of chronic kidney disease-mineral and bone disorder (CKD-MBD). Kidney Int Suppl 7, 1-59.

145. Bouillon R (2017) Comparative analysis of nutritional guidelines for vitamin D. Nat Rev Endocrinol 13, 466-479.

146. Kennel KA, Drake MT \& Hurley DL (2010) Vitamin D deficiency in adults: when to test and how to treat. Mayo Clinic Proc 85, 752-757; quiz 7-8.

147. Holick MF, Binkley NC, Bischoff-Ferrari HA, et al. (2011) Evaluation, treatment, and prevention of vitamin D deficiency: an Endocrine Society clinical practice guideline. J Clin Endocrinol Metab 96, 1911-1930.

148. Ketha H, Thacher TD, Oberhelman SS, Fischer PR, Singh RJ \& Kumar R (2018) Comparison of the effect of daily versus bolus dose maternal vitamin $\mathrm{D}(3)$ supplementation on the 24,25dihydroxyvitamin $\mathrm{D}(3)$ to 25-hydroxyvitamin $\mathrm{D}(3)$ ratio. Bone 110, 321-325.

149. Prié D \& Friedlander G (2010) Reciprocal control of 1,25-dihydroxyvitamin D and FGF23 formation involving the FGF23/ Klotho system. Clin J Am Soc Nephrol 5, 1717-1722. 
150. Charoenngam N, Rujirachun $\mathrm{P}$, Holick MF \& Ungprasert $\mathrm{P}$ (2019) Oral vitamin D(3) supplementation increases serum fibroblast growth factor 23 concentration in vitamin D-deficient patients: a systematic review and meta-analysis. Osteoporos Int 30, 2183-2193.

151. Turner C, Dalton N, Inaoui R, Fogelman I, Fraser WD \& Hampson G (2013) Effect of a 300 000-IU loading dose of ergocalciferol (Vitamin D2) on circulating 1,25(OH)2-vitamin $\mathrm{D}$ and fibroblast growth factor-23 (FGF-23) in vitamin D insufficiency. J Clin Endocrinol Metab 98, 550-556.

152. EASL (2019) Clinical practice guidelines on nutrition in chronic liver disease. J Hepatol 70, 172-193.

153. Chapman MH, Thorburn D, Hirschfield GM, et al. (2019) British Society of Gastroenterology and UK-PSC guidelines for the diagnosis and management of primary sclerosing cholangitis. Gut 68, 1356-1378.

154. Hirschfield GM, Dyson JK, Alexander GJM, et al. (2018) The British Society of Gastroenterology/UK-PBC primary biliary cholangitis treatment and management guidelines. Gut $\mathbf{6 7}$ 1568-1594.

155. Ludvigsson JF, Bai JC, Biagi F, et al. (2014) Diagnosis and management of adult coeliac disease: guidelines from the British Society of Gastroenterology. Gut 63, 1210-1228.
156. Lamb CA, Kennedy NA, Raine T, et al. (2019) British Society of Gastroenterology consensus guidelines on the management of inflammatory bowel disease in adults. Gut $\mathbf{6 8}$ (Suppl 3), s1-s106.

157. Ketteler M, Block GA, Evenepoel P, et al. (2017) Executive summary of the 2017 KDIGO Chronic Kidney DiseaseMineral and Bone Disorder (CKD-MBD) guideline update: what's changed and why it matters. Kidney Int 92, 26-36.

158. Ketteler M, Elder GJ, Evenepoel P, et al. (2015) Revisiting KDIGO clinical practice guideline on chronic kidney disease-mineral and bone disorder: a commentary from a Kidney disease: improving global outcomes controversies conference. Kidney Int 87, 502-528.

159. Moe SM \& Drüeke T (2008) Improving global outcomes in mineral and bone disorders. Clin J Am Soc Nephrol 3 (Suppl 3), S127-S130.

160. Barazzoni R, Bischoff SC, Breda J, et al. (2020) ESPEN expert statements and practical guidance for nutritional management of individuals with SARS-CoV-2 infection. Clin Nutr 39, 16311638.

161. Singer P, Blaser AR, Berger MM, et al. (2019) ESPEN guideline on clinical nutrition in the intensive care unit. Clin Nutr $\mathbf{3 8}$, 48-79. 